\title{
Developing Strategy of Clinical Practice Guidelines for Post-intensive Care Syndrome: A Systematic Review of 14 Practice Guidelines and 10 Consensus Statements
}

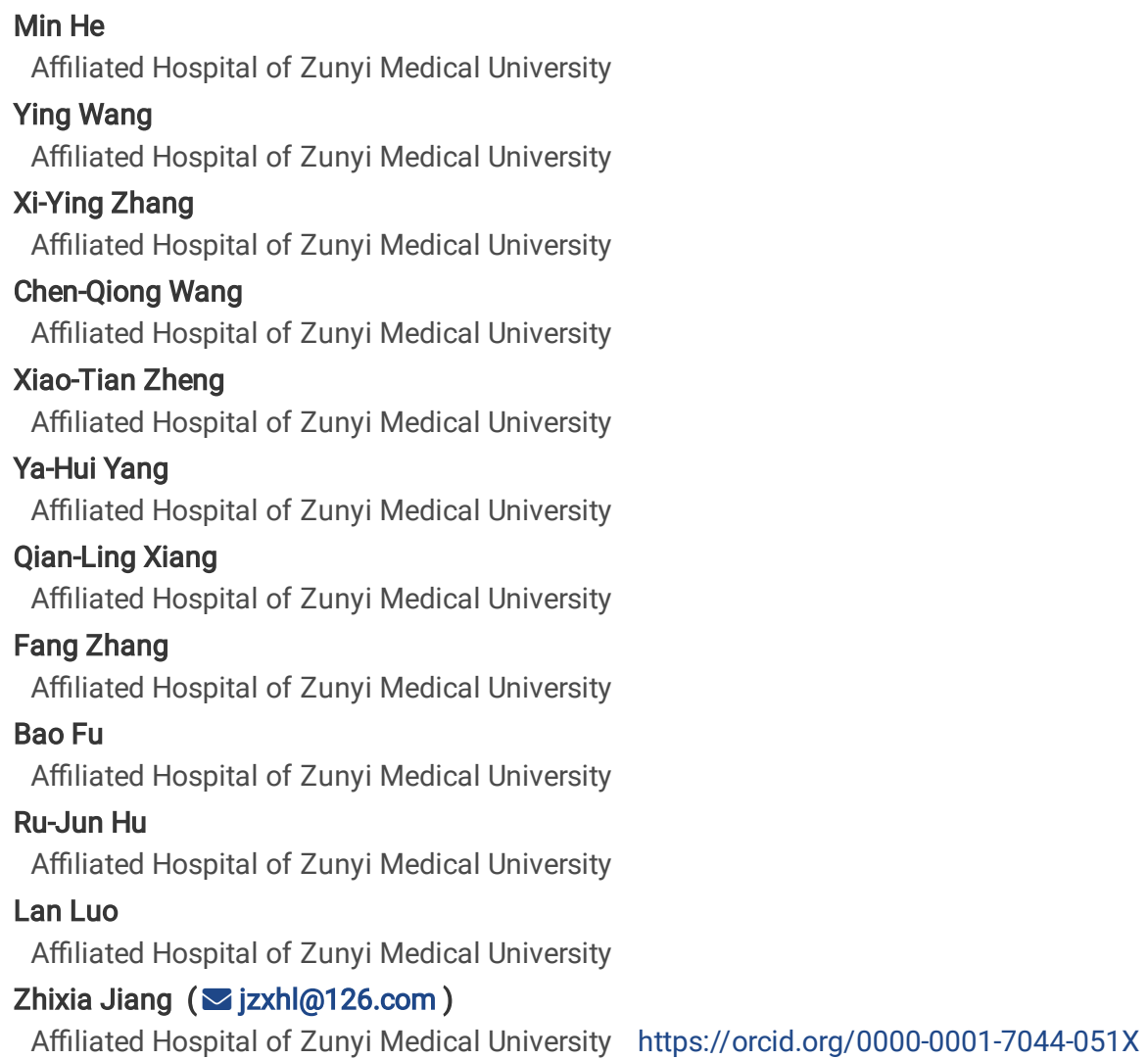

Research

Keywords: Post-intensive care syndrome (PICS), clinical practice guidelines, expert consensus statement, systematic review Posted Date: September 24th, 2020

DOI: https://doi.org/10.21203/rs.3.rs-80162/v1

License: () (i) This work is licensed under a Creative Commons Attribution 4.0 International License. Read Full License 


\section{Abstract}

Background

Post-intensive care syndrome (PICS) seriously affects the quality of life of patients and their caregivers. This study systematically evaluates PICS related guidelines and consensuses to provide methodological and strategic guidance for the development and improvement of these guidelines and consensus.

Methods

An Internet search of PICS specific or related guidelines and consensus statements was conducted among academic databases and the websites. The AGREE II was used to evaluate their methodological quality. The themes and contents were evaluated based on the definition of PICS and the "patient-clinical problem-intervention-target" framework.

Results

We included fourteen guidelines and 10 expert consensuses. The mean AGREE II score for scope and purpose was $86.89 \% \pm 16.12 \% / 79.47 \% \pm$ $11.80 \%, 55.86 \% \pm 29.17 \% / 16.72 \% \pm 16.39 \%$ for stakeholder involvement, $76.35 \% \pm 15.82 \% / 36.09 \% \pm 26.05 \%$ for rigor of development, $88.03 \% \pm$ $15.55 \% / 58.84 \% \pm 28.94 \%$ for clarity of presentation, $61.79 \% \pm 23.16 / 32.95 \% \pm 20.91 \%$ for applicability, and $66.67 \% \pm 37.96 \% / 28.79 \% \pm 36.54 \%$ for editorial independence in Guidelines/Consensus. Most only described a single or series of clinical related issues of PICS; only applicable for critically ill patients with clinical problems of ICUAW, pain, sleep disruption, agitation, and delirium. The interventions included risk assessment, monitoring/diagnosis, prevention, treatment, safety criteria, and home care of one or more symptoms of PICS.

Conclusions

Our results suggested that development and improvement of guidelines/consensus should focus on refining the methodology, strengthening quality control, and improving presentation clarity, editorial independence, and applicability. The results may provide new idea for a future guidelines and consensus statements.

\section{Background}

The concept of post-intensive care syndrome (PICS) was first proposed by the Society of Critical Care Medicine (SCCM) at the World Critical Care Congress in 2010, where it was suggested that patients with critical conditions often develop physical dysfunctions, mental disorders, and cognitive impairments in the intensive care unit (ICU), general ward, or following discharge from the hospital [1, 2]. Physical dysfunctions included ICU-acquired weakness (ICUAW) and disuse atrophy and fatigue; psychological and mental disorders included depression, anxiety, and post-traumatic stress disorder (PTSD); and cognitive and behavioral impairments included delirium, memory loss, and inattention. Moreover, due to intensive emotional turbulence, heavy care workload, and stress from a variety of sources, family members and caregivers may also develop physical and mental abnormalities. These caregivers and family members were subsequently termed the PICS-Family (PICS-F) [1, 2]. Epidemiological studies have shown that $10 \%$ to $50 \%$ of critically ill patients suffer from depression, anxiety, PTSD, and sleeping disorders; $30 \%$ to $80 \%$ have difficulty recovering their cognitive functions to the level prior to admission to the ICU; $50 \%$ to $70 \%$ are left with limited ability to perform activities of daily living (ADLs) even after a year of being discharged from the ICU. In addition, $11.1 \%$ to $45.8 \%$ of family members/caregivers were found to develop symptoms such as anxiety, depression, and PTSD. As a result, patients' quality of life is reduced and the majority have difficulty returning to society and the workplace. Family members/caregivers also suffer from heavy psychological and financial burdens.

The clinical practice guidelines are designed to assist clinicians and patients to apply evidence-based techniques to address specific problems, guide diagnosis and treatment, and standardize clinical decision-making behaviors. Hence, the guidelines are significant in improving the quality of medical services, promoting and applying new research results [3]. Moreover, scientifically developed clinical practice guidelines and experts consensus statements play a pivotal role in improving the professional knowledge and skills of medical staff, scientifically deploying medical resources, and protecting the rights and interests of patients [3].

Many studies have demonstrated inconsistencies in the methodological and reporting quality of existing guidelines/consensus statements, which reduce their effectiveness in guiding clinical practice and improving medical quality [4]. Therefore, we systematically reviewed PICS/PICS-F-related guidelines and consensus statements and analyzed their methodological and reporting quality as well as the covered themes and contents, to provide methodological and strategic guidance for the development and improvement of corresponding guidelines and consensus statements and clinical translation.

\section{Materials And Methods}

Inclusion and exclusion criteria

Page $2 / 20$ 
The inclusion criteria for the guidelines and consensus statement collection were as follows: (i) Study participants: the participants should be adult patients with a critical illness and experience with critical illness care, including patients that are hospitalized in the ICU, have transferred to a general ward, are recovering at home following discharge from hospital, or have transferred to a community or rehabilitation institution. (ii) Clinical problems: the study covered the physical, psychological, mental, cognitive, and behavioral illnesses of the surviving patients/caregivers that occurred during hospitalization in the ICU, after transfer from the ICU to a general ward, or following discharge from the hospital. Specifically, the physical dysfunctions should include neuromuscular diseases, acquired weakness, disuse atrophy or fatigue; psychological and mental disorders should include PTSD, tension, anxiety, or depression; and cognitive and behavioral impairment should include delirium, memory loss, inattention, or difficulty to return to family, society, and the workplace [5]. (iii) Interventions: The study should be relevant to the monitoring, evaluation, nursing diagnosis, prevention, treatment or management of PICS/PICS-F. Specifically, physical dysfunction interventions should generally include early mobilization and rehabilitation exercises; interventions for psychological and mental disorders should include ICU diary, mindfulness-based stress reduction (MBSR), or cognitive behavioral therapy and good communication; and interventions for cognitive and behavioral impairment should cover analgesia/sedation or the assessment, monitoring, and management of delirium and environmental management (such as light, sound). (iv) Study type: the study should be clinical practice guidelines or an expert consensus statement.

The exclusion criteria were as follows: First, the titles were reviewed to exclude duplicate records. Second, the titles and abstracts were reviewed to exclude studies of non-ICU patients and studies that were not related to guidelines/consensus statements (such as translations; abstracts, interpretations, and evaluations of guidelines; and applied research and meta-analyses). Last, all studies were reviewed to exclude those that did not cover monitoring, evaluation, diagnosis, prevention, treatment, or management of PICS/PICS-F.

\section{Search strategy}

To retrieve all PICS/PCIS-F guidelines and related guidelines, the research team determined that potentially qualified studies should either contain both terms "PICS/PICS-F" and "guidelines/consensus statement," or the term "ICU"; they should also include one or more clinical problems along with the term "guidelines/consensus statement." Therefore, two strategies were applied: (i) ("Intensive care syndrome" [Title/Abstract] OR "Postintensive care syndrome" [Title/Abstract] OR "Postintensive care syndrome" [Title/Abstract] OR "ICU-acquired weakness" [Title/Abstract] OR "ICU acquired weakness" [Title/Abstract] OR "ICU-AW" [Title/Abstract] OR "ICUAW" [Title/Abstract] OR "PICS" [Title/Abstract] OR "ICU syndrome" [Title/Abstract]) AND ("clinical guidelines" [Title/Abstract] OR "clinical guideline" [Title/Abstract] OR "clinical guidelines" [Title/Abstract] OR "clinical guideline" [Title/Abstract] OR "practice guideline" [Title/Abstract] OR "practice guidelines" [Title/Abstract] OR "clinical guidance" [Title/Abstract]OR "expert consensus" [Title/Abstract] OR "specialist consensus" [Title/Abstract] OR "clinical standard" [Title/Abstract] OR "clinical norm" [Title/Abstract] OR "clinical criterion" [Title/Abstract] OR "clinical criteria" [Title/Abstract]) \(2) ("Intensive care" [Title/Abstract] OR "ICUs" [Title/Abstract] OR “ICU” [Title/Abstract] OR “EICU” [Title/Abstract] OR "NICU” [Title/Abstract] OR “MICU” [Title/Abstract] OR “CCU” [Title/Abstract] OR "NSICU" [Title/Abstract] OR "PICU" [Title/Abstract] OR "Critical patient" [Title/Abstract] OR "Critical patients" [Title/Abstract] OR "Critically ill patients" [Title/Abstract] OR "Critically ill patient" [Title/Abstract])AND ("Anxious" [Title/Abstract] OR "Anxiety" [Title/Abstract] OR "Nervousness"

[Title/Abstract] OR "Hypervigilance" [Title/Abstract] OR "Fear" [Title/Abstract] OR "Fears" [Title/Abstract] OR "Delirium" [Title/Abstract] OR "Deliriums" [Title/Abstract] OR "depressed" [Title/Abstract] OR "Memory" [Title/Abstract] OR "Cognitive impairment" [Title/Abstract] OR "Cognitive Dysfunction" [Title/Abstract] OR “Cognitive Dysfunctions" [Title/Abstract] OR "Cognitive Impairments" [Title/Abstract] OR "Cognitive Impairment" [Title/Abstract] OR "Cognitive Decline" [Title/Abstract] OR "Cognitive Declines" [Title/Abstract] OR "Mental Deterioration" [Title/Abstract] OR "Sleep" [Title/Abstract] OR "Physical dysfunction" [Title/Abstract] OR "physiological function" [Title/Abstract] OR "Stress disorder" [Title/Abstract] OR "Pain" [Title/Abstract] OR "Agitation" [Title/Abstract] OR "Sedation" [Title/Abstract] OR “Delirium" [Title/Abstract] OR "Immobility" [Title/Abstract] OR "sedoanalgesia" [Title/Abstract] OR "rehabilitation" [Title/Abstract] OR "family" [Title/Abstract] OR "analgesics" [Title/Abstract])) AND ("clinical guidelines" [Title/Abstract] OR "clinical guideline" [Title/Abstract] OR "practice guideline" [Title/Abstract] OR "practice guidelines" [Title/Abstract] OR "clinical guidance" [Title/Abstract] OR "expert consensus" [Title/Abstract] OR "specialist consensus" [Title/Abstract] OR "clinical standard" [Title/Abstract] OR "clinical norm" [Title/Abstract] OR "clinical criterion" [Title/Abstract] OR "clinical criteria" [Title/Abstract]). Two reviewers (Cheng-Qiong Wang and Hong Jiang) tasked with the search were asked to independently apply the search strategies to obtain PICS/PCIS-F specific and related guidelines and consensus statements in both Chinese and English databases. The main databases used in this study were PubMed, Embase, Web of Science, China National Knowledge Infrastructure (CNKI), Chinese Scientific Journals Full-Text Database (VIP), Wanfang Database, and China Biological Medicine (CBM). In addition, the websites of the National Institute for Health Clinical Excellence (NICE), World Health Organization (WHO), Scottish Intercollegiate Guidelines Network (SIGN), Medlive.cn, and Registered Nurses' Association of Ontario (l'Association des infirmières et infirmiers autorisés de l'Ontario, RNAO) were also used for acquiring corresponding data (considered supplementary databases). The search range was from the establishment of the corresponding database to May 16,2020. Then, the bibliography of systematic reviews and clinical evaluations of the corresponding guidelines and consensus statements were further screened for qualified guidelines and consensus statements.

\section{Data screening}

Two reviewers (Min He and Cheng-Qiong Wang) were asked to independently screen the obtained guidelines and consensus statements based on the pre-established inclusion and exclusion criteria. Discrepancies in selection between the evaluators were resolved through discussion, and any further disagreements were resolved by a third party (Zhi-Xia Jiang).

\section{Methodology and reporting quality}


Two reviewers (Min He and Ying Wang) were asked to independently apply the Appraisal of Guidelines for Research and Evaluation (AGREE II) [6, 7] and Reporting Items for Practice Guidelines in Healthcare (RIGHT) [8, 9] to evaluate the methodological and reporting quality of the obtained guidelines and consensus statements. Disagreements in the evaluation were resolved through discussion. AGREE $\nabla$ contains 23 items from 6 domains. The reviewers rated all items on a 7-point scale (" 1 " = "strongly disagree" to "7" = "strongly agree") where the score of each domain was calculated according to the following formula: domain score = (obtained score - minimum possible score) / (maximum possible score - minimum possible score) $\times 100 \%[6,7]$. SPSS 19.0 was employed to calculate the intraclass correlation coefficient (ICC) to ensure that the understanding of the reviewers was consistent. The ICC value should be no less than 0.8 [10]. The total score of each guideline or consensus statement was the weighted sum of the domain scores. Specifically, the weighting for rigor of development and applicability was $25 \%$, while those for the other domains (i.e. scope and purpose, stakeholder involvement, clarity of presentation, and editorial independence) were $12.5 \%$ [11]. A total score greater than $60 \%$ indicated that the guideline or consensus statement is highly recommended, a score greater than $30 \%$ but less than or equal to $60 \%$ indicated that the guideline/consensus statement would be recommended following revision, and a score equal to or less than $30 \%$ indicated that the guideline or consensus statement is not recommended [4]. RIGHT includes seven sectors: basic information, background, evidence, recommendations, review and quality assurance, funding, declaration and management of interests, and other information (access, suggestions for future research, and limitations of guidelines), with 22 items in the list. Full conformity of each item equals 1 point, while partial conformity or non-conformity means 0 points. The final score was calculated as follows: obtained score / maximum possible score $\times 100 \%$. The results reflect the reporting quality of each evaluation domain and the overall guideline/consensus statement [8].

\section{Data extraction}

Two independent reviewers (Min He and Xi-Ying Zhang) were asked to use a pre-developed information extraction table to independently extract and cross-check the data. Disagreements regarding the extraction were resolved through discussion and/or involvement of a third reviewer (Zhi-Xia Jiang). The basic information that was extracted included the first author, the year of publication/release, region or country of publication, theme, target population, applicable population, and applicable organization. The methodological quality features extracted included basic information, background, evidence, recommendations, review and quality assurance, funding, declaration and management of interests, and other information (access, suggestions for future research, and limitations of guidelines). The reporting quality features extracted included scope and purpose, stakeholder involvement, clarity of presentation, editorial independence, rigor of development, and applicability. The content structure features were extracted that included PICS/PICS-F related clinical problems (physical dysfunctions, psychological and mental disorders, and cognitive and behavioral impairments of patients/caregivers) and the interventions taken (monitoring, diagnosis, prevention, and treatment).

\section{Statistical analysis}

According to the AGREE $\otimes$ and RIGHT evaluation criteria, each evaluation domain/sector was expressed as a percentage. For the domains/sectors with scores that satisfied a normal distribution, the mean and standard deviation were calculated (); otherwise, the median and quartile values were used for descriptive analysis. The summary of the descriptive analysis was used to analyze the basic information and theme of the guidelines and consensus statements; the "definitions of PICS/PICS-F" and the "patient-clinical problem-intervention-target" framework were introduced to analyze the content structure; and a combination of the content structure, prevention and treatment measures, and "ICU-general ward-community/family" framework was adopted to visually construct a PICS/PICS-F management model.

\section{Results}

\section{Data screening process and results}

A total of 1,591 records were extracted from the main databases. Of these, 567 records were removed due to duplication and 986 due to not containing the term "ICU" or lacking guideline and consensus statement content. Four additional records were included following review of the bibliography of the obtained records. A search in the supplementary databases yielded 3 additional guidelines. After excluding records that focused explicitly on medication, as well as all duplicates, 32 research papers were retained for analysis, including 19 guidelines and 11 expert consensus statements (Figure.1).

\section{Basic characteristics}

The systematic search and screening process yielded no PICS-specific guidelines; in total, 32 guidelines and consensus statements reporting related content, such as risk factors, monitoring, diagnosis, evaluation, prevention, and treatment of PICS and PICS-F were retrieved (Table.1). The 19 guidelines dated from 2002 to May 2020. After excluding the guidelines that were updated to other included versions, 14 guidelines were eventually retained (13 evidence-based guidelines and one general guideline). Majority of the guidelines were published by organizations from European countries (such as the United Kingdom, Germany, and Spain), North America (mainly the United States), Asian countries (such as China and Japan), and Oceania (mainly Australia). The organizations included the SCCM, the American College of Critical Care Medicine (ACCM), SIGN, Pan-American and Iberian Federation of Societies of Critical Medicine and Intensive Therapy (PAIFSCMIT), NICE, and the Chinese Medical Association (CMA). Four of the guidelines were developed through multinational cooperation [12-15], nine were developed by the corresponding state [16-24], and one was developed by a hospital [25]. In addition, the guidelines were divided into single and bundled theme guidelines. Single guidelines included the 
prevention, management and non-pharmacological intervention of delirium [15, 16, 21], ICUAW diagnosis [20], rest and sleep improvement [25], rehabilitation of critically ill patients [24], and family-centered care [14]. Bundled guidelines included sedation/analgesia [17], management of PAD $[12,19,22]$, and prevention and management of PASDIS [13]. Of these, nine guidelines that covered sedation/analgesia, family-centered care and PAD bundling management [26-31] were updated, indicating good continuity and timeliness. Across all guidelines, the main applicable population was critically ill adult patients. Only a few guidelines described the primary disease of the patient or were applicable to caregivers and family members. The main applicable institutions were ICUs, whilst guidelines applicable for standardized general wards, primary and secondary health care institutions, communities, and homecare were limited. The main targeted users were multidisciplinary professional and technical personnel in ICUs, while guidelines for primary health care professionals and community and family caregivers were insufficient.

The screened 10 expert consensus statements were dated between 2013 and 2019, including six evidence-based consensus statements [32-37]. The consensus statements that were published by academic organizations focused on critical cardiac, respiratory, and neurological care, from China, New Zealand, Canada, the United Kingdom, and Australia independently. Only the consensus statements that focused on the rehabilitation of discharged patients [34], physiotherapy for ICU patients [35], and safety criteria of active mobilization for mechanically ventilated patients [37] were developed through cross-regional cooperation. The themes covered in the consensus statements included the rehabilitation of ICU or hospital discharged patients [34, 38-43], safety criteria for the early mobilization of mechanically ventilated patients [37], sedation/analgesia for ICU patients [33], delirium management [32], and physical therapy [35]. The majority of the consensus statements had individual themes rather than being a bundled theme. Only one consensus statement clearly defined PICS/PICS-F and provided physical therapy guidelines to prevent PICS/PICS-F [34]. Seven consensus statements clearly defined the primary disease stages and the applicable population, including patients with severely critical respiratory, cardiovascular, and neurological systems; and mechanically ventilated patients [33, 36-43]. The remaining three consensus statements cited only critically ill patients or patients who survived severe illness. Only one consensus statement identified its users as ICU physical therapists [42]. All consensus statements were applicable to the ICU, however; but only one was applicable to patients following discharge from the hospital. None were developed for in-patients transferred from the ICU.

\section{Methodological quality}

The AGREE-II scores of the guidelines were as follows (Figure.2): (1) The mean for scope and purpose was $86.89 \%$ ( $\pm 16.12 \%$ ). Specifically, 13 guidelines clearly described the purpose, specific clinical problems, and patients targeted; only one guideline did not clearly report its scope and purpose. (2) The mean for stakeholder involvement was $55.86 \%( \pm 29.17 \%)$. Specifically, seven guidelines described the fields of specialization of the experts involved; 10 introduced the applicable population; five specified the views and choices of the target patients. (3) The mean for rigor of development was $76.35 \%$ ( $\pm 15.82 \%)$. Specifically, four guidelines provided evidence retrieval steps and screening processes; eight clearly specified the strengths and weaknesses of the evidence selection process; nine explained how the recommendations were formed and the association between the recommendations and evidence; seven presented the health benefits, adverse effects, and risks of the recommendations, and 10 provided the comments given by external experts and future updates plans. (4) The mean for the clarity of presentation was $88.03 \%$ ( $\pm 15.55 \%$ ). Specifically, the main recommendations of 10 guidelines were clear and identifiable and the remaining nine guidelines were clear and provided multiple options for a given clinical problem. (5) The mean for applicability was $61.79 \%( \pm 23.16 \%)$. Specifically, nine guidelines included likely facilitating and hindering factors during application; eight provided suggestions on ways to apply the recommendations in practice and the support tools required; seven explained the potential resource input issues during application; six specified the standards for monitoring the use of guidelines. (6) The mean for editorial independence was $66.67 \%( \pm 37.96 \%)$, where eight guidelines declared the relationship of interest between the sponsors and recommendations and four provided any conflicts of interest between the editing team members and recommendations made. According to the overall AGREE-II score, 11 guidelines had satisfactory methodological quality (> 60\%) and could be recommended. The scope and purpose, rigor of development, and clarity of presentation of the investigated guidelines were of high quality. However, stakeholder involvement (participially the involvement of patients/caregivers), applicability, and editorial independence required further improvement in quality.

The AGREE-II scores of the 10 expert consensus statements (six of which were evidence-based) were as follows (Figure.3): (1) The mean for scope and purpose was $79.47 \%( \pm 11.80 \%)$. The investigated consensus statements all described the purpose and targeted clinical problems and patients. (2) The mean for stakeholder involvement was $16.72 \%( \pm 16.39 \%)$. Only two consensus statements specified the applicable population, one considered the viewpoints and choices provided by the target patients, and all 10 provided the authors' professional background. (3) The mean for rigor of development was $36.09 \%( \pm 26.05 \%)$. Only two statements provided evidence of the retrieval and screening processes, three explained the strengths and weaknesses of evidence selection processes, and only one elaborated on the relationship between the supporting evidence and the recommendations and its formulation process. In addition, none of the consensus statements were reviewed by external experts prior to publication, and only two provided an update plan. (4) The mean for clarity of presentation was $58.84 \%( \pm 28.94 \%)$. Specifically, six included clear and readable recommendations, and three clearly listed different recommendations for a given clinical problem. (5) The mean for applicability was $32.95 \%$ $( \pm 20.91 \%)$. Only four consensus statements explained the potential facilitating and hindering factors during the application process, three provided suggestions and supporting tools for applying the recommendations, two introduced standards for supervision and auditing, and none of the consensus statement explained the impact of recommendations on potential resource allocation. (6) The mean for editorial independence was $28.79 \%$ ( $\pm 36.54 \%)$. Specifically, three consensus statements declared that no conflict of interest existed between the sponsors, editing team members, and the recommendations made. The overall scores revealed that only one consensus statement was methodologically qualified (>60\%) and could be recommended. The quality in terms of scope and purpose of the investigated consensus statements was high. However, the quality of 
the remaining domains, such as rigor of development, clarity of presentation, editorial independence, and applicability, was low. It was evident that the methodological quality of the consensus statements required improvement, particularly in their rigor of development and applicability. Moreover, six of the consensus statements were evidence-based, indicating that evidence-based decision-making concepts and techniques have begun to be applied to the development of consensus statements.

\section{Reporting quality}

The mean for the overall RIGHT score of the 14 guidelines (35 items) was $58.16 \%( \pm 30.31 \%)$. Specifically, 23 items were found to have a reporting quality of greater than or equal to $50 \%$. Items with higher reporting quality included $1 \mathrm{a}, 1 \mathrm{~b}, 4,7 \mathrm{a}$, and $13 \mathrm{a}$ (100.0\%), while items with lower reporting quality included $18 \mathrm{a}$ and $18 \mathrm{~b}(0 \%)$. For quality by domain, basic information, guideline background, evidence, recommendations, and other information had higher reporting ratings, while insufficient information was provided in terms of rationale/explanation for recommendations, reviews and quality assurance, funding source(s), and the role(s) of the funding parties (Table 2).

The mean overall RIGHT score for the 10 consensus statements $[22,32,33,35-43]$ was $36.57 \%$ ( $\pm 35.33 \%)$. Specifically, 23 items were found to have a reporting quality rating of greater than or equal to $50 \%, 5$ items had a reporting quality of $100 \%(1 \mathrm{a}, 1 \mathrm{~b}, 1 \mathrm{c}, 4$, and $7 \mathrm{a})$, while 10 items had a reporting quality of $0 \%(3,8 b, 10 a, 10 b, 14 a, 14 b, 18 a, 18 b, 19 b$, and 20). For domain-focused quality of reporting, basic information, background of the guidelines, recommendations, and other information had higher reporting ratings. However, the quality of reporting for health problems, evidence sources and evaluations, rationale/explanation for the recommendations, reviews and quality assurance, funding sources and declarations, management of interest, and funder's access to the consensus statements was insufficient (Table 2).

\section{Content features of the guidelines/consensus statements}

This study included 14 clinical practice guidelines (13 evidence-based) [12-25] and 10 translational consensus statements (6 evidence-based) [22, 32, 33, 35-43]. Based on definitions framework of the PICS/PICS-F, the analysis revealed that only one consensus statement clearly defined PICS/PICS-F, while the remaining documents only described one category of clinical problems normally attributed to PICS/PICS-F. Regarding physical dysfunctions, there was more focus on ICU-AW, acquired neuromuscular diseases, sleep disorders, and pain. Regarding psychological and mental disorders, the majority of guidelines and consensus statements focused on agitation, anxiety, and depression; there was insufficient focus on the PTSD of ICU patients and their family members. Regarding cognitive and behavioral disorders, the focus was on delirium; however, limited attention was given to persistent cognitive deficits and difficulties returning to the family, society, and workplace (Table.3).

An analysis based on the "patient-clinical problem-intervention-target" framework revealed that the guidelines and consensus statements covered patients that suffered cardiac and severe respiratory illnesses and acute respiratory distress syndrome (ARDS), patients that were mechanically ventilated, treated by extracorporeal membrane oxygenation (ECMO), or suffered from brain trauma, as well as ICU survivors and the caregivers of these patients. However, many of the guidelines mentioned critically ill patients without providing information on the primary diseases. Secondly, regarding clinical problem, only one consensus statement provided a definition of PICS/PICS-F. In addition, the majority of the guidelines and consensus statements provided a clear introduction of ICUAW, pain, anxiety, sleep disorders, depression, agitation, and delirium. Some only described the rehabilitation of critically ill patients without clear provisions of specific clinical problems. Thirdly, regarding interventions, most of the guidelines and consensus statements clearly illustrated measures such as ICUAW diagnosis, physical therapy, early mobilization and safety criteria, sleep management, sedation/analgesia, anxiety/depression management, risk, monitoring, prevention and management of delirium, and family-centered care. Several guidelines/consensus statements employed bundling strategies to tackle the problems and design interventions. Some guidelines only described the rehabilitation of critically ill patients but did not clarify the specific rehabilitation interventions utilized. Finally, regarding management target, the majority of the guidelines and consensus statements focused on solving sleep problems, pain (sedation/analgesia), anxiety/depression, and delirium during ICU hospitalization; only one guideline focused on physical therapy to prevent the occurrence of PICS/PICS-F, and no guidelines or consensus statement discussed the patients/caregivers/family members' quality of life or patients' difficulty in returning to the family, workplace, and society. Moreover, it was found that the guidelines on the rest and sleep management ICU patients developed by Elliott \& McKinley[25], which were formulated using an evidence-based strategy based on internal data collected from their own hospital, could effectively improve the guideline's clinical translational effects (Table.3).

\section{Discussion}

PICS/PICS-F seriously affects the quality of life of patients and their caregivers and increases the financial burden of patients' families [1, 2]. Therefore, clinical practice guidelines and expert consensus statements are urgently needed to guide scientific prevention, standardized diagnosis, and treatment of the syndrome. However, the quality of such guidelines and consensus statements serves as a guarantee and priority to promote high-quality translational effects [4]. Hence, we systematically evaluated PICS/PICS-F related clinical practice guidelines and expert consensus statements and analyzed their methodological and reporting quality. We expected that the findings could provide methodological guidance for the development and improvement of future guidelines and consensus statements.

Following a pre-designed search and screening method, 14 guidelines [12-25] and 10 consensuses statements [22, 32, 33, 35-43] were obtained. Systematic review of these showed that the majority were evidence-based guidelines (13 of the guidelines) and consensus statements (six of the 
consensus statements), indicating that evidence-based decision-making techniques have become the main technique for developing guidelines and consensus statements. AGREE-II was introduced to analyze the methodological quality of the obtained documents. The results showed that 11 guidelines could be recommended ( $>60 \%)$. In addition, the scope and purpose, rigor of development, and clarity of presentation of the investigated guidelines were higher quality areas, while stakeholder involvement (the involvement of patients/caregivers), applicability, and editorial independence required further improvement in quality. However, only one of the 10 consensus statements identified scored $>60 \%$ and could be recommended. The quality of the domains such as scope and purpose of the investigated consensus statements was high, while that of the remaining domains such as rigor of development, clarity of presentation, editorial independence, and applicability was generally low. It was evident that the methodological quality of the consensus statements required further improvement, particularly regarding rigor of development and applicability. Six of the consensus statements were evidence-based, indicating that the development of consensus statements also employs evidence-based decision-making. Moreover, detailed and clear reporting of guidelines/consensus statements are important conditions for successful clinical translation. This study used the RIGHT checklist to further evaluate the reporting quality of the included guidelines/consensus statements. The results revealed that the reporting quality was good in terms of basic information, background, evidence, recommendations, and other information regarding the guidelines, while rationale/explanation for recommendations, review and quality assurance, funding source(s), and role(s) of funders were insufficiently reported. The reporting of basic information, background, recommendations, and other information of the consensus statements was of satisfactory quality; however, the reporting of health problems, evidence sources and evaluations, rationale/explanation for recommendations, review and quality assurance, funding and declarations, and management of interests, as well as who had access to the consensus statements, was insufficient. In summary, all analyzed guidelines and consensus statements demonstrated varied limitations. Compared to the guidelines, the core methodological sections of the consensus statements (health problem, evidence sources and evaluations, rationale/explanation for recommendations) were significantly incomplete. Both the guidelines and consensus statements had problems regarding the reporting of reviews, quality control, conflict of interest, and accessibility. Therefore, the development and improvement of guidelines/consensus statements should focus on refining the methodology, strengthening quality control, and improving presentation clarity, editorial independence, and applicability.

Among the retrieved documents, one expert consensus statement covered the use of physical therapy to prevent PICS. No guidelines or consensus statements provided a definition of PICS/PICS-F. However, based on other 14 PICS/PICS-F related guidelines [12-25] and nine consensus statements, the rehabilitation management of patients suffering from critical respiratory and cardiovascular illnesses (including mechanically ventilated patients) and nervous system diseases, and treatment by prevention and management of PASDIS, ICUAW, early mobilization safety criteria, and provision of family-centered care were the main focuses. Regarding the techniques used, multi-disciplinary cooperation, cross-regional cooperation, and bundling appeared to become prominent characteristics in the development of guidelines and consensus statements.

PICS occurs during ICU hospitalization and continues even after transfer to the general ward or discharge from the hospital. Analysis based on the provided definitions of PICS/PICS-F suggested that PICS/PICS-F is a multi-disciplinary problem, involving patients, caregivers, and family members, lasting through the entire "ICU-general ward-community/family" period [1, 2]. However, existing guidelines and consensus statements generally cover only one or a limited series of clinical problems and do not focus on PTSD, persistent cognitive deficits, and difficulties in returning to family, society or workplace caused by PICS/PICS-F. From our analysis, the majority of the guidelines and consensus statements only focused on the ICU hospitalization period and ignored the period in which the patients are transferred to a general ward or discharged from the hospital. There was also insufficient attention given to caregivers/family members. Given that PICS/PICS-F is a multidisciplinary problem, future guidelines/consensus statements should clearly define PICS/PICS-F and comprehensively consider measures that cover the periods following discharge from the ICU as well as the interests of the caregivers/family members.

PICS/PICS-F is likely to develop among critically ill patients and their caregivers when the patients are in the ICU or have transferred to the general ward following discharge from the ICU. However, the incidence among caregivers can be disregarded. Critically ill patients usually suffer from a primary disease and are in critical status; consequently, patients are likely to be placed in different ICU environments and receive specialized or comprehensive treatment, which affects the incidence of PICS/PICS-F. Moreover, the severity and symptoms of PICS/PICS-F vary significantly when the patients are in the ICU, post-ICU, and post-hospitalization periods. The analysis based on the "patient-clinical problem-intervention-target" framework showed that a majority of the guidelines and consensus statements only mentioned critically ill patients instead of clearly reporting the primary disease of the patients. More focus was on the acquired weakness, pain, anxiety, sleep disorder, depression, agitation, and delirium of critically ill patients when they are in the ICU, while less attention was paid to those transferred from ICU to the general ward and community/family. Moreover, the specific clinical problems of patients were not clearly specified. As a result, the existing guidelines and consensus statements are not able to scientifically guide the management of PICS/PICS-F treatment. Thus, future guidelines and consensus statements should clearly define the disease characteristics and ICU characteristics of the applicable population and pay more attention to the differences in patients' clinical problems between ICU, post-ICU, and post-hospitalization periods, as well as the needs of the caregivers/family members.

Based on the characteristics of the target population and clinical problems, recommended intervention measures include prevention, treatment, and quality control and safety precautions. Prevention measures mostly focus on risk assessment, confirmation of risk factors and causes, and implementation of preventive interventions such as pharmacological, non-pharmacological, and physical therapies to reduce the incidence. Treatment measures generally focus on disease monitoring/diagnosis, adopting early detection and treatment as the core principle, and usage of pharmacological, non-pharmacological, and physical therapies to eliminate the disease or reduce its harm. Quality control and safety precautions measures normally emphasized involve strengthening of quality control and elimination/reduction of safety problems to improve the quality of life of

Page $7 / 20$ 
patients/caregivers and assist them in returning to family, workplace, and society. The "patient-clinical problem-intervention-target" framework analysis showed that the guidelines/consensus statements only discussed risk assessment, prevention, monitoring/diagnosis, treatment (pharmacological, non-pharmacological, and physical therapies), safety criteria, and family care. The purpose of the guidelines/consensus statements was mostly limited to solving clinical problems during the ICU stage; less attention was paid to the problems that occur in the general wards, the community at large, and the family after discharge from the ICU. The adoption of bundling strategies to integrate issues and interventions were mostly emphasized; however, quite a few of the guidelines and consensus statements did not clearly describe the precise intervention measures used. The majority of the guidelines and consensus statements included two major themes: prevention and treatment. However, the intervention measures tended to be complex and inconsistent, and the goals of the intervention measures were not clear. Therefore, future guidelines and consensus statements should specify the patients' goals, establish clear risk assessment-based interventions with an introduction of risk factors and cause of the diseases, as well as a management system based on monitoring/diagnosis and treatment of PICS/PICS-F. We also found that the guidelines for rest and sleep management of ICU patients developed by Elliott \& McKinley adopted an evidence-based strategy[25]. The approach realized a systematic integration of the specific information on clinical problems and evidence-based strategy, providing new ideas for the development of future guidelines.

Based on the multi-disciplinary and full-process attributes of the applicable population and clinical problems, we propose that multi-disciplinary cooperation, bundling, evidence-based decision-making, and systematic integration of local information should be the core techniques for developing evidence-based PICS/PICS-F prevention and treatment guidelines. The guidelines should cover the clinical problems that occur throughout the entire period from when the patients enter the ICU, to being transferred to the general ward, and returning to community and family. Further, they should consider the interest of both patients and caregivers/family members. Prevention and treatment should be at the core of the guidelines' content. Prevention systems should focus on critically ill patients (primary diseases) as a starting point, emphasizing the assessment of risk factors/causes, prediction, and prevention (pharmacological, non-pharmacological, and physical therapies), and reducing the incidence of cases. The treatment system should focus on critically ill patients (primary disease) as a starting point, emphasizing monitoring/diagnosis and ensuring early detection and treatment (pharmacological, non-pharmacological, and physical therapies, psychological and behavioral therapy, and family therapy), to eventually alleviate or eliminate the impact of PICS/PICS-F, and improve the quality of care, helping patients to successfully return to their families, workplaces, and society (Figure 4). From the above analysis, there is currently a shortage of PICS specific guidelines from both home and abroad, which emphasizes the urgency of developing improved guidelines. Future development of guidelines and consensus statements should focus on refining the methodology, strengthening quality control, and improving presentation clarity, editorial independence, and applicability. Multidisciplinary cooperation, bundling, and evidence-based decision-making techniques should form the basis of managing guidelines/consensus statements.

\section{Limitations}

This study has several limitations: (1) Although two search strategies were employed, certain search biases may remain. (2) This study used the AGREE- $\triangle$ and RIGHT checklists to evaluate the guidelines/consensus statements. Although the evaluators received training prior to conducting

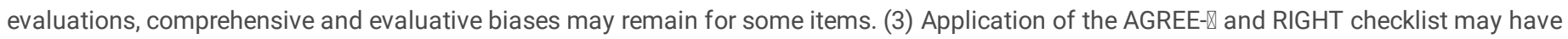
reduced the perceived methodological and reporting quality of the consensus statements. (4) As the information related to the application of the guidelines/consensus statement was not accessible, the effects of implementation were not included in the evaluation.

\section{Conclusion}

Currently, there is a lack of PICS specific guidelines worldwide, necessitating the development of such guidelines. Multidisciplinary cooperation, bundling and evidence-based decision-making techniques, and organic integration of localized information should be the basis for managing the development of corresponding guidelines and consensus statements, focusing on refining the methodology, strengthening quality control, and improving presentation clarity, editorial independence, and applicability. Developers of future guidelines/consensus statements should focus on prevention and treatment of PICS/PICS-F, integrate multidisciplinary features, and the overall well-being of both patients and caregivers/family members. It is expected that the findings of this study will serve as a reference for developing future PICS/PICS-F guidelines.

\section{Key messages}

- We included fourteen guidelines and 10 expert consensuses, but without PICS specific guidelines worldwide, necessitating the development of such guidelines.

- Multidisciplinary cooperation, bundling and evidence-based decision-making techniques, and organic integration of localized information should be the basis for managing the development of corresponding guidelines and consensus statements, focusing on refining the methodology, strengthening quality control, and improving presentation clarity, editorial independence, and applicability.

- Developers of future guidelines/consensus statements should focus on prevention and treatment of PICS/PICS-F, integrate multidisciplinary features, and the overall well-being of both patients and caregivers/family members.

\section{Abbreviations}


ADLs: activities of daily living; ACCM: The American College of Critical Care Medicine; ANZIC-RC: Australian and New Zealand Intensive Care Research Centre; ARDS: acute respiratory distress syndrome; AGREE II: Appraisal of the Guidelines for Research and Evaluation; CBM: China Biological Medicine; CMA: Chinese Medical Association; CG: clinical guideline; CECOS: Chinese Expert Committee on severe cardiac sedation and analgesia; CNKI: China National Knowledge Infrastructure; DSIT: Danish Society of Intensive Care Medicine; DASAIM: Danish Society of Anesthesiology and Intensive Care Medicine; DGAI: German Society of Anaesthesiology and Intensive Care Medicine ); ECMO: extracorporeal membrane oxygenation; EBG: evidence-based guideline; EBC: Evidence based consensus; ECBG: Evidence and consensus-based guidelines; ICU: intensive care unit; ICUAW: ICU-acquired weakness; ICC: intraclass correlation coefficient; JSICM: Japanese Society of Intensive Care Medicine; MBSR: mindfulness-based stress reduction; NICE: National Institute for Health Clinical Excellence; PICS: Post-intensive care syndrome; PAD: pain, agitation, and delirium; PTSD: post-traumatic stress disorder; PICS-F: Post-intensive care syndrome-Family; PAIFSCMIT: Pan-American and Iberian Federation of Societies of Critical Medicine and Intensive Therapy; PASDIS: Pain, Agitation/Sedation, Delirium, Immobility, and Sleep Disruption; RIGHT: Reporting Items for Practice Guidelines in Healthcare; RMAC: Rehabilitation Medical Association in China; SCCM: Society of Critical Care Medicine; SIGN: Scottish Intercollegiate Guidelines Network; USA: United States of America; UK: The United Kingdom of Great Britain and Northern Ireland; VIP: Chinese Scientific Journals Full-Text Database; WHO: World Health Organization.

\section{Declarations}

\section{Acknowledgements}

None.

\section{Funding}

This work was supported by Fund of Zunyi science and Technology Bureau (Zunshi Kehe she Zi, No. 91, 2018) and China Research Hospital Association fund (Zun Zi He Zi, No. 14, 2018).

\section{Availability of data and materials}

The datasets used and/or analyzed during the current study are available from the corresponding or first author on reasonable request.

\section{Authors' Contributions}

Conception and design by Zhi-Xia Jiang, Bao Fu and Min He; development of methodology by Cheng-Qiong Wang, Min He, and Ru-Jun Hu; Study search by Min He, Ying Wang and Ru-Jun Hu; selection of eligible trials by Cheng-Qiong Wang and Min He; assessment of methodological bias risk by Min He and Xiao-Tian Zheng; data extraction by Min He and Ying Wang; statistical analysis by Min He, Ying Wang, preparing the manuscript draft by Min He, Zhi-Xia Jiang, Ying Wang, Xi-Ying Zhang, Qian-Ling Xiang, Fang Zhang, Lan Luo; and study supervision by Zhi-Xia Jiang; All authors read and approved the final version of the manuscript .

\section{Ethics approval and consent to participate}

This manuscript did not require review by the Institutional Review Board or consent, as all participants analyzed were from published data.

\section{Consent for publication}

Not applicable.

\section{Competing interests}

None of the authors of this manuscript have any financial interest related to this meta-analysis.

\section{Author details}

1.Department of Nursing, Affiliated Hospital of Zunyi Medical University, Zunyi 563003, Guizhou, China.

2.School of Nursing, Zunyi Medical University, Zunyi 563003, Guizhou, China.

3.Evidence-Based Medicine Center, MOE Virtual Research Center of Evidence-based Medicine at Zunyi Medical College, Affiliated Hospital of Zunyi Medical University, Zunyi 563003, Guizhou, China.

4.School of Management, Zunyi Medical University, Zunyi 563003, Guizhou, China.

5.Department of Emergency, Affiliated Hospital of Zunyi Medical University, Zunyi 563003, Guizhou, China.

6.Department of critical care medicine, Affiliated Hospital of Zunyi Medical University, Zunyi 563003, Guizhou, China. 


\section{References}

1. Inoue S, Hatakeyama J, Kondo Y, Hifumi T, Sakuramoto H, Kawasaki T, Taito S, Nakamura K, Unoki T, Kawai Y et al: Post-intensive care syndrome: its pathophysiology, prevention, and future directions. Acute Med Surg 2019, 6(3):233-246.

2. Huggins EL, Bloom SL, Stollings JL, Camp M, Sevin CM, Jackson JC: A Clinic Model: Post-Intensive Care Syndrome and Post-Intensive Care Syndrome-Family. AACN Adv Crit Care 2016, 27(2):204-211.

3. Lameire N, Van Biesen W: Clinical practice guidelines: an important tool in improving dialysis quality. Contrib Nephro/ 2012, 178:58-67.

4. Jiang M, Guan WJ, Fang ZF, Xie YQ, Xie JX, Chen H, Wei D, Lai KF, Zhong NS: A Critical Review of the Quality of Cough Clinical Practice Guidelines. Chest 2016, 150(4):777-788.

5. Needham DM, Davidson J, Cohen H, Hopkins RO, Weinert C, Wunsch H, Zawistowski C, Bemis-Dougherty A, Berney SC, Bienvenu OJ et al: Improving long-term outcomes after discharge from intensive care unit: report from a stakeholders' conference. Crit Care Med 2012, 40(2):502509.

6. Bazzano AN, Green E, Madison A, Barton A, Gillispie V, Bazzano LA: Assessment of the quality and content of national and international guidelines on hypertensive disorders of pregnancy using the AGREE II instrument. BMJ Open 2016, 6(1):e009189.

7. Loder E, Burch R, Rizzoli P: The 2012 AHS/AAN guidelines for prevention of episodic migraine: a summary and comparison with other recent clinical practice guidelines. Headache 2012, 52(6):930-945.

8. Chen Y, Yang K, Marušic A, Qaseem A, Meerpohl JJ, Flottorp S, Akl EA, Schünemann HJ, Chan ES, Falck-Ytter Y et al: A Reporting Tool for Practice Guidelines in Health Care: The RIGHT Statement. Ann Intern Med 2017, 166(2):128-132.

9. Chen Y, Yang K, Marusic A, Qaseem A, Meerpohl JJ, Flottorp S, Akl EA, Schunemann HJ, Chan ESY, Falck-Ytter Y et al: [A reporting tool for practice guidelines in health care: the RIGHT statement]. Z Evid Fortbild Qual Gesundhwes 2017, 127-128:3-10.

10. Chen Y, Zhou Q, Cui R, Yang N, Xiao S, Shang H: Quality evaluation of Traditional Chinese Medicine guidelines based on AGREE $\mathrm{I}$ Instrument. Chin J EBM 2016, 16(11):1331-1337.

11. Jiang M, Liao LY, Liu XQ, He WQ, Guan WJ, Chen H, Li YM: Quality Assessment of Clinical Practice Guidelines for Respiratory Diseases in China: A Systematic Appraisal. Chest 2015, 148(3):759-766.

12. Celis-Rodriguez E, Diaz Cortes JC, Cardenas Bolivar YR, Carrizosa Gonzalez JA, Pinilla DI, Ferrer Zaccaro LE, Birchenall C, Caballero Lopez J, Arguello BM, Castillo Abrego $\mathrm{G}$ et al: Evidence-based clinical practice guidelines for the management of sedoanalgesia and delirium in critically ill adult patients. Med Intensiva 2020, 44(3):171-184.

13. Devlin JW, Skrobik Y, Gélinas C, Needham DM, Slooter AJC, Pandharipande PP, Watson PL, Weinhouse GL, Nunnally ME, Rochwerg B et al: Clinical Practice Guidelines for the Prevention and Management of Pain, Agitation/Sedation, Delirium, Immobility, and Sleep Disruption in Adult Patients in the ICU. Critical Care Medicine 2018, 46(9):e825-e873.

14. Davidson JE, Aslakson RA, Long AC, Puntillo KA, Kross EK, Hart J, Cox CE, Wunsch H, Wickline MA, Nunnally ME et al: Guidelines for FamilyCentered Care in the Neonatal, Pediatric, and Adult ICU. Crit Care Med 2017, 45(1):103-128.

15. Abraha I, Rimland JM, Trotta F, Pierini V, Cruz-Jentoft A, Soiza R, O'Mahony D, Cherubini A: Non-Pharmacological Interventions to Prevent or Treat Delirium in Older Patients: Clinical Practice Recommendations The SENATOR-ONTOP Series. J Nutr Health Aging 2016, 20(9):927-936.

16. Network SIG: Risk reduction and management of delirium. wwwsignacuk 2019

17. Society of critical care medicine CMA: Guidelines for analgesia and sedation treatment in intensive care unit of Chinese adults. Chin Crit Care Med 2018, 30(6):497-514.

18. Fonsmark L, Hein L, Nibroe H, Bundgaard H, de Haas I, Iversen S, Strom T: Danish national sedation strategy. Targeted therapy of discomfort associated with critical illness. Danish Society of Intensive Care Medicine (DSIT) and the Danish Society of Anesthesiology and Intensive Care Medicine (DASAIM). Danish Medical Journal 2015, 62(4).

19. Medicine JSoIC: Japanese guidelines for the management of Pain, Agitation, and Delirium in intensive care unit (J-PAD). J Jpn Soc Intensive Care Med 2014, 21:539-579.

20. Fan E, Cheek F, Chlan L, Gosselink R, Hart N, Herridge MS, Hopkins RO, Hough CL, Kress JP, Latronico N et al: An official American Thoracic Society Clinical Practice guideline: the diagnosis of intensive care unit-acquired weakness in adults. Am J Respir Crit Care Med 2014, 190(12):1437-1446

21. NICE: Delirium: prevention, diagnosis and management. wwwniceorguk/guidance/cg103 2010.

22. Martin J, Heymann A, Basell K, Baron R, Biniek R, Burkle H, Dall P, Dictus C, Eggers V, Eichler I et al: Evidence and consensus-based German guidelines for the management of analgesia, sedation and delirium in intensive care-short version. German medical science : GMS e-journal 2010, 8:Doc02-Doc02.

23. García Mozo A, Sánchez Roldán F, Amorós Cerdá SM, Balaguer Albarracín F, Díez Alcalde M, Durán Torres MT, González Gascue M, Lastra Cubel P, Sánchez Calvín C, Zaforteza Lallemand C: Development of an attention guideline for the critical patient's family. Enfermeria Intensiva 2010, 21(1):20-27.

24. NICE: Rehabilitation after critical illness in adults. wwwniceorguk/guidance/cg83 2009. 
25. Elliott R, McKinley S: The development of a clinical practice guideline to improve sleep in intensive care patients: A solution focused approach. Intensive and Critical Care Nursing 2014, 30(5):246-256.

26. Celis-Rodriguez E, Birchenall C, de la Cal MA, Castorena Arellano G, Hernandez A, Ceraso D, Diaz Cortes JC, Duenas Castell C, Jimenez EJ, Meza $\mathrm{JC}$ et al: Clinical practice guidelines for evidence-based management of sedoanalgesia in critically ill adult patients. Med Intensiva 2013 , 37(8):519-574.

27. Celis-Rodríguez E, Besso J, Birchenall C, de la Cal MA, Carrillo R, Castorena G, Ceraso D, Dueñas C, Gil F, Jiménez E et al: Clinical practice guideline based on the evidence for the management of sedoanalgesia in the critically ill adult patient. Med Intensiva 2007, 31(8):428-471.

28. Society of critical care medicine CMA: Guidelines for sedation and analgesia in critical ill patients (2006). Chin J Pract Surg 2006, 26(12):893901.

29. Jacobi J, Fraser GL, Coursin DB, Riker RR, Fontaine D, Wittbrodt ET, Chalfin DB, Masica MF, Bjerke HS, Coplin WM et al: Clinical practice guidelines for the sustained use of sedatives and analgesics in the critically ill adult. Crit Care Med 2002, 30(1):119-141.

30. Barr J, Fraser GL, Puntillo K, Ely EW, Gelinas C, Dasta JF, Davidson JE, Devlin JW, Kress JP, Joffe AM et al: Clinical practice guidelines for the management of pain, agitation, and delirium in adult patients in the intensive care unit. Crit Care Med 2013, 41(1):263-306.

31. Davidson JE, Powers K, Hedayat KM, Tieszen M, Kon AA, Shepard E, Spuhler V, Todres ID, Levy M, Barr J et al: Clinical practice guidelines for support of the family in the patient-centered intensive care unit: American College of Critical Care Medicine Task Force 2004-2005. Critical Care Medicine 2007, 35(2):605-622.

32. Tang B, Wang X, Chen W, Zhu S, Chao Y, Zhu B, He W, Wang B, Cao F, Liu Y et al: Experts consensus on the management of delirium in critically ill patients. Chin J Intern Med 2019, 58(2):108-118.

33. China ECoSCSaAi: Expert consensus on cardiac sedation and analgesia in China. Natl Med J China 2017, 97(10):726-734.

34. Major ME, Kwakman R, Kho ME, Connolly B, McWilliams D, Denehy L, Hanekom S, Patman S, Gosselink R, Jones C et al: Surviving critical illness: what is next? An expert consensus statement on physical rehabilitation after hospital discharge. Crit Care 2016, 20(1):354.

35. Sommers J, Engelbert RHH, Dettling-Ihnenfeldt D, Gosselink R, Spronk PE, Nollet F, van der Schaaf M: Physiotherapy in the intensive care unit: an evidence-based, expert driven, practical statement and rehabilitation recommendations. Clinical Rehabilitation 2015, 29(11):1051-1063.

36. Wei J, Kang D, Zhao Y, Hu J, Jiang R, Shi G, Cai W, Wang N, Gao L, Sun S et al: Expert consensus on critical care management in neurosurgery (2013). Chin J Cerebrovasc Dis 2013, 10(08):436-448.

37. Hodgson CL, Stiller K, Needham DM, Tipping CJ, Harrold M, Baldwin CE, Bradley S, Berney S, Caruana LR, Elliott D et al: Expert consensus and recommendations on safety criteria for active mobilization of mechanically ventilated critically ill adults. Crit Care 2014, 18(6):658.

38. Severe respiratory rehabilitation group SrpcoRMAiC, China AhsasboghcMRAi, Care ECCJG, Beijing Xrhi: Expert consensus on severe respiratory rehabilitation in China. Chin J Geriatr Care 2018, 16(5):3-11.

39. Ni Y, Wang S, Song W, Li B, Chen J, Feng Z, Guo L, He Z, Huang H, Jiang L et al: Experts consensus on severe neurological rehabilitation in China (). Chin J Rehab Med 2018, 33(3):264-268.

40. Ni Y, Wang S, Song W, Li B, Chen J, Feng Z, Guo L, He Z, Huang H, Jiang L et al: Experts consensus on severe neurological rehabilitation in China (). Chin J Rehab Med 2018, 33(1):7-14.

41. Ni Y, Wang S, Song W, Li B, Chen J, Feng Z, Guo L, He Z, Huang H, Jiang L et al: Experts consensus on severe neurological rehabilitation in China (). Chin J Rehab Med 2018, 33(2):130-136.

42. Lin J: Expert consensus on critical care rehabilitation in Zhejiang Province. Zhejiang Med J 2017, 39(24):2191-2196,2209.

43. Association CM, China CcmcgoNi: Expert consensus on early rehabilitation management of severe traumatic brain injury in China (2017). Natl Med J China 2017, 97(21):1615-1623.

\section{Tables}




\section{Table 1. Basic characteristics of included studies}

The systematic search and screening process yielded no PICS-specific guidelines; in total, 32 guidelines and consensus statements reporting related content, such as risk factors, monitoring, diagnosis, evaluation, prevention, and treatment of PICS and PICS-F were retrieved.

\begin{tabular}{|c|c|c|c|c|c|c|c|}
\hline Author (Years) & Country & Organization & Topics & Target population & Types & Target users & Settings \\
\hline \multicolumn{8}{|c|}{ Table 1a. Clinical practice guidelines } \\
\hline $\begin{array}{l}\text { Celis-Rodriguez, } \\
\text { E,2020[12] }\end{array}$ & $\begin{array}{l}\text { Colombia, } \\
\text { Spain, } \\
\text { Mexico, } \\
\text { Chile (9 } \\
\text { countries) }\end{array}$ & PAIFSCMIT & $\begin{array}{l}\text { The } \\
\text { management of } \\
\text { sedoanalgesia } \\
\text { and delirium }\end{array}$ & $\begin{array}{l}\text { Critically ill adult } \\
\text { patient. }\end{array}$ & EBG & $\begin{array}{l}\text { Physicians, } \\
\text { nurses and } \\
\text { physiotherapists } \\
\text { (therapists) }\end{array}$ & ICU \\
\hline SIGN,2019[16] & Scotland & $\begin{array}{l}\text { Scottish } \\
\text { Intercollegiate } \\
\text { Guidelines } \\
\text { Network }\end{array}$ & $\begin{array}{l}\text { Risk reduction } \\
\text { and } \\
\text { management of } \\
\text { delirium }\end{array}$ & $\begin{array}{l}\text { Inpatient/Intensive } \\
\text { care patients }\end{array}$ & EBG & $\begin{array}{l}\text { Primary and } \\
\text { secondary } \\
\text { healthcare } \\
\text { professionals, } \\
\text { community and } \\
\text { care home staff }\end{array}$ & $\begin{array}{l}\text { Home, long- } \\
\text { term care, } \\
\text { hospital, and } \\
\text { hospice }\end{array}$ \\
\hline CMA,2018[17] & China & $\begin{array}{l}\text { Chinese } \\
\text { Medical } \\
\text { Association }\end{array}$ & $\begin{array}{l}\text { Guidelines for } \\
\text { analgesia and } \\
\text { sedation in } \\
\text { Chinese }\end{array}$ & $\begin{array}{l}\text { Adult severe } \\
\text { patients }\end{array}$ & EBG & $\begin{array}{l}\text { Critical medical } \\
\text { workers (not } \\
\text { specific) }\end{array}$ & ICU \\
\hline $\begin{array}{l}\text { Devlin, J. W, } \\
\text { 2018[13] }\end{array}$ & $\begin{array}{l}\text { USA, } \\
\text { Canada, } \\
\text { Australia, } \\
\text { France, } \\
\text { Netherlands }\end{array}$ & ACCM,SCCM & $\begin{array}{l}\text { Prevention and } \\
\text { management of } \\
\text { PASDIS in adult } \\
\text { patients }\end{array}$ & $\begin{array}{l}\text { Adult severe } \\
\text { patients }\end{array}$ & EBG & Clinicians & ICU \\
\hline $\begin{array}{l}\text { Davidson, J. } \\
\text { E,2017[14] }\end{array}$ & $\begin{array}{l}\text { USA, } \\
\text { Canada, } \\
\text { France, } \\
\text { Israel, } \\
\text { Germany, } \\
\text { New } \\
\text { Zealand, } \\
\text { Netherlands }\end{array}$ & Unclear & $\begin{array}{l}\text { Family-centered } \\
\text { care in the } \\
\text { neonatal, } \\
\text { pediatric, and } \\
\text { adult ICU }\end{array}$ & $\begin{array}{l}\text { Neonatal, pediatric } \\
\text {, adult severe } \\
\text { patients }\end{array}$ & EBG & ICU clinicians. & ICU \\
\hline $\begin{array}{l}\text { Abraha, } \\
\text { I,2016[15] }\end{array}$ & $\begin{array}{l}\text { Italy, Spain, } \\
\text { United } \\
\text { Kingdom, } \\
\text { Ireland (4 } \\
\text { countries) }\end{array}$ & Unclear & $\begin{array}{l}\text { Non- } \\
\text { pharmacological } \\
\text { Interventions to } \\
\text { prevent or treat } \\
\text { delirium }\end{array}$ & $\begin{array}{l}\text { Delirium older } \\
\text { patients }\end{array}$ & EBG & Not reported & $\begin{array}{l}\text { General ward, } \\
\text { family, ICU }\end{array}$ \\
\hline $\begin{array}{l}\text { Fonsmark, L , } \\
\text { 2015[18] }\end{array}$ & Danish & DSIT/DASAIM & $\begin{array}{l}\text { Targeted therapy } \\
\text { of discomfort } \\
\text { associated with } \\
\text { critical illness }\end{array}$ & $\begin{array}{l}\text { Majority of } \\
\text { patients general } \\
\text { ICU }\end{array}$ & CG & Not reported & ICU \\
\hline $\begin{array}{l}\text { JSICM,2014 } \\
\text { [19] }\end{array}$ & Japan & $\begin{array}{l}\text { Japanese } \\
\text { Society of } \\
\text { Intensive Care } \\
\text { Medicine }\end{array}$ & $\begin{array}{l}\text { Management of } \\
\text { Pain, Agitation, } \\
\text { and Delirium in } \\
\text { intensive care } \\
\text { unit }\end{array}$ & $\begin{array}{l}\text { Adult severe } \\
\text { patients }\end{array}$ & EBG & $\begin{array}{l}\text { Doctor, nurse, } \\
\text { pharmacist, } \\
\text { physiotherapist, } \\
\text { clinical } \\
\text { engineering } \\
\text { engineer. }\end{array}$ & ICU \\
\hline Fan, E,2014 [20] & USA & $\begin{array}{l}\text { American } \\
\text { Thoracic } \\
\text { Society }\end{array}$ & $\begin{array}{l}\text { The diagnosis of } \\
\text { intensive care } \\
\text { unit-acquired } \\
\text { weakness }\end{array}$ & $\begin{array}{l}\text { Adult severe } \\
\text { patients }\end{array}$ & EBG & Not reported & ICU \\
\hline $\begin{array}{l}\text { Elliott, R } 2014 \\
\text { [25] }\end{array}$ & Australia & $\begin{array}{l}\text { Royal North } \\
\text { Shore } \\
\text { Hospital }\end{array}$ & $\begin{array}{l}\text { Rest and sleep } \\
\text { guideline }\end{array}$ & $\begin{array}{l}\text { Intensive care } \\
\text { patients }\end{array}$ & EBG & Not reported & $\begin{array}{l}\text { General, } \\
\text { neurosurgical } \\
\text { and } \\
\text { cardiothoracic } \\
\text { adult ICU }\end{array}$ \\
\hline $\begin{array}{l}\text { García Mozo, A } \\
\text {,2010 [23] }\end{array}$ & Spain & Unclear & $\begin{array}{l}\text { Guideline for the } \\
\text { critical patient's } \\
\text { family }\end{array}$ & $\begin{array}{l}\text { Critically ill adult } \\
\text { patient. }\end{array}$ & EBG & $\begin{array}{l}\text { Doctors, nurses, } \\
\text { physiotherapists. }\end{array}$ & ICU \\
\hline $\begin{array}{l}\text { Martin, J } \\
, 2010[22]\end{array}$ & German & DGAI & $\begin{array}{l}\text { The } \\
\text { management of } \\
\text { analgesia, } \\
\text { sedation and } \\
\text { delirium }\end{array}$ & Critically ill patient & ECBG & $\begin{array}{l}\text { All ICU } \\
\text { professionals }\end{array}$ & ICU \\
\hline NICE,2010[21] & UK & NICE & $\begin{array}{l}\text { Delirium: } \\
\text { prevention, }\end{array}$ & $\begin{array}{l}\text { Patient and carer, } \\
\text { family members }\end{array}$ & EBG & NHS staff & $\begin{array}{l}\text { Hospital, } \\
\text { residential } \\
\text { care settings }\end{array}$ \\
\hline
\end{tabular}


diagnosis and management

$\begin{array}{lllll}\text { NICE,2009[24] UK } & \text { NICE } & \begin{array}{l}\text { Rehabilitation } \\ \text { after critical } \\ \text { illness in adults }\end{array} & \begin{array}{l}\text { Patient and carer, } \\ \text { family members }\end{array} & \begin{array}{l}\text { EBG } \\ \text { ICU, } \\ \text { rechabilitation } \\ \text { institutions, } \\ \text { family }\end{array}\end{array}$

Table-1b.Expert consensus

\begin{tabular}{|c|c|c|c|c|c|c|c|}
\hline $\begin{array}{l}\text { Tang, } \\
\text { B,2019[32] }\end{array}$ & China & $\begin{array}{l}\text { Chinese } \\
\text { Critical } \\
\text { Hypothermia } \\
\text {-Sedation } \\
\text { Therapy } \\
\text { Study Group }\end{array}$ & $\begin{array}{l}\text { Management of } \\
\text { delirium }\end{array}$ & Severe patients & EBC & Not reported & $\mathrm{ICU}$ \\
\hline RMAC,2018 [38] & China & $\begin{array}{l}\text { Rehabilitation } \\
\text { Medical } \\
\text { Association in } \\
\text { China }\end{array}$ & $\begin{array}{l}\text { Respiratory } \\
\text { rehabilitation }\end{array}$ & $\begin{array}{l}\text { Severe respiratory } \\
\text { patients }\end{array}$ & Consensus & Not reported & ICU \\
\hline $\begin{array}{l}\mathrm{Ni}, \mathrm{Y}, 2018 \text { [39- } \\
41]\end{array}$ & China & Unclear & $\begin{array}{l}\text { Severe } \\
\text { neurological } \\
\text { rehabilitation }\end{array}$ & $\begin{array}{l}\text { Severe neurologic } \\
\text { patients }\end{array}$ & Consensus & Not reported & $\mathrm{ICU}$ \\
\hline CMA,2017 [43] & China & CMA & $\begin{array}{l}\text { Early } \\
\text { rehabilitation } \\
\text { management }\end{array}$ & $\begin{array}{l}\text { Severe } \\
\text { craniocerebral } \\
\text { trauma patients }\end{array}$ & Consensus & Not reported & ICU \\
\hline CECOS,2017[33] & China & CECOS & $\begin{array}{l}\text { Sedation and } \\
\text { analgesia }\end{array}$ & $\begin{array}{l}\text { Adult patients with } \\
\text { severe heart } \\
\text { disease }\end{array}$ & EBC & Not reported & ICU \\
\hline Lin,J,2017[42] & China & $\begin{array}{l}\text { Zhejiang } \\
\text { Medical } \\
\text { Association }\end{array}$ & $\begin{array}{l}\text { Early } \\
\text { rehabilitation }\end{array}$ & $\begin{array}{l}\text { Brain/spinal cord } \\
\text { injury, respiratory } \\
\text { /heart failure,ICU- } \\
\text { AW }\end{array}$ & Consensus & $\begin{array}{l}\text { Physiotherapist, } \\
\text { ICU }\end{array}$ & $\mathrm{ICU}$ \\
\hline $\begin{array}{l}\text { Major, M. } \\
\text { E,2016[34] }\end{array}$ & $\begin{array}{l}\text { Netherlands, } \\
\text { Canada, UK, } \\
\text { Australia, } \\
\text { Belgium, } \\
\text { USA }\end{array}$ & $\begin{array}{l}\text { University of } \\
\text { Applied } \\
\text { Sciences }\end{array}$ & $\begin{array}{l}\text { Physical therapy } \\
(\mathrm{PT}) \text { in the } \\
\text { rehabilitation of } \\
\text { critical illness } \\
\text { survivors after } \\
\text { hospital } \\
\text { discharge }\end{array}$ & $\begin{array}{l}\text { Critical illness } \\
\text { survivors }\end{array}$ & EBC & Not reported & ICU \\
\hline $\begin{array}{l}\text { Sommers, J, } \\
2015 \text { [35] }\end{array}$ & $\begin{array}{l}\text { Netherlands, } \\
\text { Belgium }\end{array}$ & $\begin{array}{l}\text { Amsterdam } \\
\text { University }\end{array}$ & $\begin{array}{l}\text { Physiotherapy in } \\
\text { the ICU }\end{array}$ & ICU patients & EBC & Not reported & ICU \\
\hline $\begin{array}{l}\text { Hodgson, C. } \\
\text { L,2014 [37] }\end{array}$ & $\begin{array}{l}\text { Australia, } \\
\text { New } \\
\text { Zealand, } \\
\text { USA, } \\
\text { Finland }\end{array}$ & ANZIC-RC & $\begin{array}{l}\text { Safety criteria } \\
\text { for active } \\
\text { mobilization }\end{array}$ & $\begin{array}{l}\text { Mechanically } \\
\text { ventilated critically } \\
\text { ill adults }\end{array}$ & $\mathrm{EBC}$ & Not reported & ICU \\
\hline Wei, J,2013 [36] & China & $\begin{array}{l}\text { Chinese } \\
\text { Medical } \\
\text { Association }\end{array}$ & $\begin{array}{l}\text { Neurosurgery } \\
\text { critical care } \\
\text { management }\end{array}$ & $\begin{array}{l}\text { Adult } \\
\text { neurosurgery } \\
\text { patients }\end{array}$ & EBC & Not reported & ICU \\
\hline
\end{tabular}

Note: ACCM: The American College of Critical Care Medicine; ANZIC-RC: Australian and New Zealand Intensive Care Research Centre; CG: clinical guideline; CECOS: Chinese Expert Committee on severe cardiac sedation and analgesia; EBG: evidence-based guideline; EBC: Evidence based consensus; ECBG: Evidence and consensus-based guidelines; DSIT: Danish Society of Intensive Care Medicine; DASAIM: Danish Society of Anesthesiology and Intensive Care Medicine; DGAl: German Society of Anaesthesiology and Intensive Care Medicine ); ICU: Intensive care unit; JSICM: Japanese Society of Intensive Care Medicine; NICE: National Institute for Health and Care Excellence; CMA: Chinese Medical Association; PAIFSCMIT: Pan-American and Iberian Federation of Societies of Critical Medicine and Intensive Therapy; PASDIS: Pain, Agitation/Sedation, Delirium, Immobility, and Sleep Disruption; RMAC: Rehabilitation Medical Association in China; SCCM: Society of Critical Care Medicine; SIGN: Scottish Intercollegiate Guidelines Network; USA: United States of America; UK: The United Kingdom of Great Britain and Northern Ireland. 


\begin{tabular}{|c|c|c|c|c|}
\hline Section & topic & Item & Guidelines & Consensus \\
\hline \multirow[t]{6}{*}{ Basic information } & \multirow[t]{3}{*}{ Title/subtitle } & $\begin{array}{l}\text { 1a.Identify the report as a guideline, that is, with "guideline(s)" or } \\
\text { "recommendation(s)" in the title. }\end{array}$ & $14(100.00 \%)$ & $10(100 \%)$ \\
\hline & & 1b.Describe the year of publication of the guideline. & $14(100.00 \%)$ & $10(100 \%)$ \\
\hline & & 1c.Describe the focus of the guideline & $13(92.85 \%)$ & $10(100 \%)$ \\
\hline & Executive summary & $\begin{array}{l}\text { 2.Provide a summary of the recommendations contained in the } \\
\text { guideline. }\end{array}$ & $12(85.71 \%)$ & $5(50.00 \%)$ \\
\hline & $\begin{array}{l}\text { Abbreviations and } \\
\text { acronyms }\end{array}$ & $\begin{array}{l}\text { 3.Define new or key terms, and provide a list of abbreviations } \\
\text { and acronyms if applicable. }\end{array}$ & $3(21.42 \%)$ & $0(0.00 \%)$ \\
\hline & $\begin{array}{l}\text { Corresponding } \\
\text { developer }\end{array}$ & $\begin{array}{l}\text { 4.Identify at least one corresponding developer or author who } \\
\text { can be contacted about the guideline. }\end{array}$ & $14(100.00 \%)$ & $10(100 \%)$ \\
\hline \multirow[t]{8}{*}{ Background } & $\begin{array}{l}\text { Description of health } \\
\text { problem(s) }\end{array}$ & 5.Describe the basic epidemiology of the problem. & $9(64.28 \%)$ & $8(80.00 \%)$ \\
\hline & $\begin{array}{l}\operatorname{Aim}(s) \text { and specific } \\
\text { objectives }\end{array}$ & 6.Describe the aim(s) of the guideline and specific objectives. & $11(78.57 \%)$ & $7(70.00 \%)$ \\
\hline & \multirow[t]{2}{*}{ Target population(s) } & $\begin{array}{l}\text { 7a.Describe the primary population(s) that is addressed by the } \\
\text { recommendation(s) in the guideline. }\end{array}$ & $14(100.00 \%)$ & $10(100 \%)$ \\
\hline & & $\begin{array}{l}\text { 7b. Describe any subgroups that are given special consideration } \\
\text { in the guideline. }\end{array}$ & $7(50.00 \%)$ & $1(10.00 \%)$ \\
\hline & \multirow[t]{2}{*}{$\begin{array}{l}\text { End- users and } \\
\text { settings }\end{array}$} & $\begin{array}{l}\text { 8a.Describe the intended primary users and other potential users } \\
\text { of the guideline. }\end{array}$ & $8(57.14 \%)$ & $2(20.00 \%)$ \\
\hline & & 8b.Describe the setting(s) for which the guideline is intended. & $3(21.42 \%)$ & $0(0.00 \%)$ \\
\hline & \multirow[t]{2}{*}{$\begin{array}{l}\text { Guideline } \\
\text { development groups }\end{array}$} & $\begin{array}{l}\text { 9a.Describe how all contributors to the guideline development } \\
\text { were selected and their roles and responsibilities }\end{array}$ & $8(57.14 \%)$ & $2(20.00 \%)$ \\
\hline & & 9b.List all individuals involved in developing the guideline. & $10(71.42 \%)$ & $9(90.00 \%)$ \\
\hline \multirow[t]{5}{*}{ Evidences } & \multirow[t]{2}{*}{ Healthcare questions } & 10a.Healthcare questions & $9(64.28 \%)$ & $0(0.00 \%)$ \\
\hline & & 10b.Indicate how the outcomes were selected and sorted. & $5(35.71 \%)$ & $0(0.00 \%)$ \\
\hline & \multirow[t]{2}{*}{ Systematic reviews } & $\begin{array}{l}\text { 11a.Indicate whether the guideline is based on new systematic } \\
\text { reviews done specifically for this guideline }\end{array}$ & $10(71.42 \%)$ & $3(30.00 \%)$ \\
\hline & & $\begin{array}{l}11 \mathrm{~b} \text {. If the guideline developers used existing systematic } \\
\text { reviews, reference these and describe how those reviews were } \\
\text { identified and assessed and whether they were updated. }\end{array}$ & $10(71.42 \%)$ & $3(30.00) \%$ \\
\hline & $\begin{array}{l}\text { The certainty of the } \\
\text { evidence body }\end{array}$ & $\begin{array}{l}\text { 12.Describe the approach used to assess the certainty of the } \\
\text { body of evidence. }\end{array}$ & $12(85.71 \%)$ & $2(20.00) \%$ \\
\hline \multirow[t]{7}{*}{ Recommendations } & \multirow[t]{3}{*}{ Recommendations } & 13a.Provide clear, precise, and actionable recommendations. & $14(100.00 \%)$ & $7(70.00 \%)$ \\
\hline & & $\begin{array}{l}\text { 13b.Present separate recommendations for important } \\
\text { subgroups. }\end{array}$ & $8(57.14 \%)$ & $2(20.00 \%)$ \\
\hline & & $\begin{array}{l}\text { 13c. Indicate the strength of recommendations and the certainty } \\
\text { of the supporting evidence. }\end{array}$ & $13(92.85 \%)$ & $5(50.00 \%)$ \\
\hline & \multirow[t]{3}{*}{$\begin{array}{l}\text { Rationale/explanation } \\
\text { for recommendations }\end{array}$} & $\begin{array}{l}\text { 14a.Describe whether values and preferences of the target } \\
\text { population(s) were considered }\end{array}$ & $4(28.57 \%)$ & $0(0.00 \%)$ \\
\hline & & $\begin{array}{l}\text { 14b.Describe whether cost and resource implications were } \\
\text { considered in the formulation of recommendations. }\end{array}$ & $2(14.28 \%)$ & $0(0.00 \%)$ \\
\hline & & $\begin{array}{l}\text { 14c.Describe other factors taken into consideration when } \\
\text { formulating the recommendations }\end{array}$ & $2(14.28 \%)$ & $1(10.00 \%)$ \\
\hline & $\begin{array}{l}\text { Evidence to decision } \\
\text { processes }\end{array}$ & $\begin{array}{l}\text { 15.Describe the processes and approaches used by the } \\
\text { guideline development group to make decisions }\end{array}$ & $11(78.57 \%)$ & $4(40.00 \%)$ \\
\hline \multirow[t]{2}{*}{$\begin{array}{l}\text { Review and quality } \\
\text { assurance }\end{array}$} & External review & $\begin{array}{l}\text { 16.Indicate whether the draft guideline underwent independent } \\
\text { review. }\end{array}$ & $3(21.42 \%)$ & $1(10.00 \%)$ \\
\hline & Quality assurance & $\begin{array}{l}\text { 17.Indicate whether the guideline was subjected to a quality } \\
\text { assurance process. }\end{array}$ & $3(21.42 \%)$ & $1(10.00 \%)$ \\
\hline Funding, declaration & Funding source(s) & 18a.Describe the specific sources of funding for all stages of & $0(0.00 \%)$ & $0(0.00 \% \rrbracket$ \\
\hline
\end{tabular}




\begin{tabular}{|c|c|c|c|c|}
\hline \multirow{4}{*}{$\begin{array}{l}\text { and management of } \\
\text { interest }\end{array}$} & \multirow{2}{*}{$\begin{array}{l}\text { and role(s) of the } \\
\text { funder }\end{array}$} & \multicolumn{3}{|l|}{ guideline development. } \\
\hline & & 18b.Describe the role of funder(s) in the different stages. & $0(0.00 \%)$ & $0(0.00 \%)$ \\
\hline & \multirow{2}{*}{$\begin{array}{l}\text { Declaration and } \\
\text { management of } \\
\text { interest }\end{array}$} & $\begin{array}{l}\text { 19a.Describe what types of conflicts (financial and non- } \\
\text { financial) were relevant to guideline development. }\end{array}$ & $8(57.14 \%)$ & $3(30.00)$ \\
\hline & & $\begin{array}{l}\text { 19b.Describe how conflicts of interest were evaluated and } \\
\text { managed and how users can access the declarations. }\end{array}$ & $2(14.28 \%)$ & $0(0.00 \%)$ \\
\hline \multirow[t]{3}{*}{ Other information } & Access & $\begin{array}{l}\text { 20.Describe where the guideline, its appendices, and other } \\
\text { related documents can be accessed. }\end{array}$ & $9(64.28 \%)$ & $0(0.00 \%)$ \\
\hline & $\begin{array}{l}\text { Suggestions for } \\
\text { further research }\end{array}$ & $\begin{array}{l}\text { 21.Describe the gaps in the evidence and/or provide } \\
\text { suggestions for future research. }\end{array}$ & $12(85.71 \%)$ & $7(70.00 \%)$ \\
\hline & $\begin{array}{l}\text { Limitations of the } \\
\text { guideline }\end{array}$ & $\begin{array}{l}\text { 22.Describe any limitations in the guideline development } \\
\text { process. }\end{array}$ & $8(57.14 \%)$ & $5(50.00 \%)$ \\
\hline
\end{tabular}

For quality by domain, basic information, guideline background, evidence, recommendations, and other information had higher reporting ratings, while insufficient information was provided in terms of rationale/explanation for recommendations, reviews and quality assurance, funding source(s), and the role(s) of the funding parties.

The quality of reporting for health problems, evidence sources and evaluations, rationale/explanation for the recommendations, reviews and quality assurance, funding sources and declarations, management of interest, and funder's access to the consensus statements was insufficient. 


\section{Table. 3 The content features of the guidelines/consensus statements}

Based on definitions framework of the PICS/PICS-F, the analysis revealed that only one consensus statement clearly defined PICS/PICS-F, while the remaining documents only described one category of clinical problems normally attributed to PICS/PICS-F.

An analysis based on the "patient-clinical problem-intervention-target" framework revealed that the guidelines and consensus statements covered patients that suffered cardiac and severe respiratory illnesses and acute respiratory distress syndrome (ARDS), patients that were mechanically ventilated, treated by extracorporeal membrane oxygenation (ECMO), or suffered from brain trauma, as well as ICU survivors and the caregivers of these patients.

\begin{tabular}{|c|c|c|c|}
\hline Author (Years) & Themes & Post-intensive care syndrome/ post-intensive care syndrome-family(PICS/PICS-F) & Types \\
\hline CMA,2018 [38] & $\begin{array}{l}\text { Respiratory } \\
\text { rehabilitation }\end{array}$ & $\begin{array}{l}\text { The assessment, treatment, nursing, and quality management of respiratory severe } \\
\text { rehabilitation; common complications and treatment }\end{array}$ & Consensus \\
\hline CNCCM,2017[43] & $\begin{array}{l}\text { Early } \\
\text { rehabilitation }\end{array}$ & Early rehabilitation management of severe traumatic brain injury & Consensus \\
\hline Lin, J.2017 [42] & $\begin{array}{l}\text { Early } \\
\text { rehabilitation }\end{array}$ & Early rehabilitation treatment of ICU- acquired weakness(ICU-AW) & Consensus \\
\hline NICE,2009 [24] & Rehabilitation & ICUAW nursing process & EBG \\
\hline
\end{tabular}
$\mathrm{Ni}, \mathrm{Y}, 2018[39-$
Neurological
Evaluation and management of delirium, depression and acquired neuromyopathy $\mathbb{}$
Consensus

41]

Major, M.E,2016 Physical

management of fear, pain, restlessness, analgesia, sedation and exercise

[34]

therapy (PT)

PT goals, measurement tools, and optimal PT intervention for survivors of critical illness

EBC

Sommers,

$\mathrm{J}, 2015$ [35]

Physiotherapy

after hospital discharge

Hodgson, $\mathrm{C}$

The safety criteria of mobilization and activation; clinimetrics and their psychometric properties to quantify physical functions and activities; physiotherapy interventions to improve physical functions and activities.

L,2014 [37] $\quad$ mobilization

Safety criteria for active mobilization of mechanically ventilated critically ill adults

EBC

Fan, E,2014 [20]

The diagnosis

The diagnosis of intensive care unit-acquired weakness in adults

EBG

of ICU-AW

Elliott, R,2014 Rest and sleep Improve sleep in intensive care patients

EBG

[25]

Celis-Rodriguez, Sedoanalgesia $\mathrm{E}, 2020[12] \quad$ and delirium

CMA,2018 [17] Analgesia and sedation

Devlin, J. W,2018 PASDIS

[13]

CECOS,2017 [33] Sedation and analgesia

Martin, J,2010 Analgesia,

[22] delirium

JSICM,2014 [19] PAD

Management of pain, agitation, and delirium

EBG

Fonsmark, L,2015 [18]

Discomfort associated with critical illness

ABCDEF bundle; the benefits and management strategies of pain, sedation, and analgesia in patients with cardiovascular impairment, sepsis and septic shock, ARDS and ECMO, and oncological patient; identification, prediction, prevention and management of delirium; persistent cognitive deficit.

The assessment, treatment and monitoring of pain, anxiety and agitation; delirium and its prevention and treatment; complications of analgesia and sedation;

The assessment, prevention, and treatment of pain, agitation/sedation, delirium, immobility (mobilization/rehabilitation), and sleep (disruption)

Anxiety and restlessness prevention; Delirium monitoring and prevention

EBC

Risk factors, monitoring, therapy of analgesia, sedation and delirium

EBG

Wei, J, 2013 [36] $\begin{aligned} & \text { Neurosurgery } \\ & \text { critical care }\end{aligned}$

Wei, J, $2013[36] \quad \begin{aligned} & \text { Neurosurgery } \\ & \text { critical care }\end{aligned}$

Tang, B ,2019 Delirium

[32]

SING,2019 , , , , , Delirium

Identification and treatment of anxiety disorders, sleep disorders, delirium

CG

Tools for detection and assessment, measuring severity of delirium, and detecting incident delirium in hospital; clinical investigations; non-pharmacological risk reduction (Inpatient care/Intensive care)

Abraha, l,2016 Delirium

[15]

Non-pharmacological interventions(multicomponent and single component) to prevent or treat delirium in older patients

NICE,2010 [21] Delirium Delirium: prevention, diagnosis and management.

Davidson, J. Family-

Communication with family members, family presence, family support, consultations and
EBC

EBC

EBG

EBG

EBG

EBG 


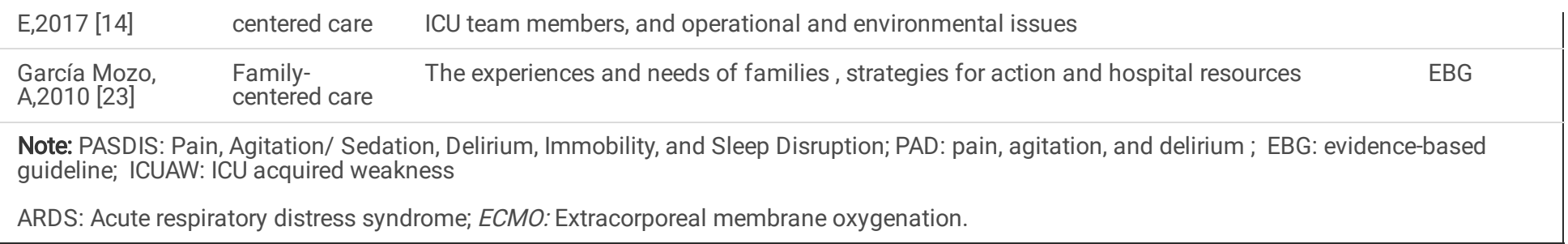

\section{Figures}

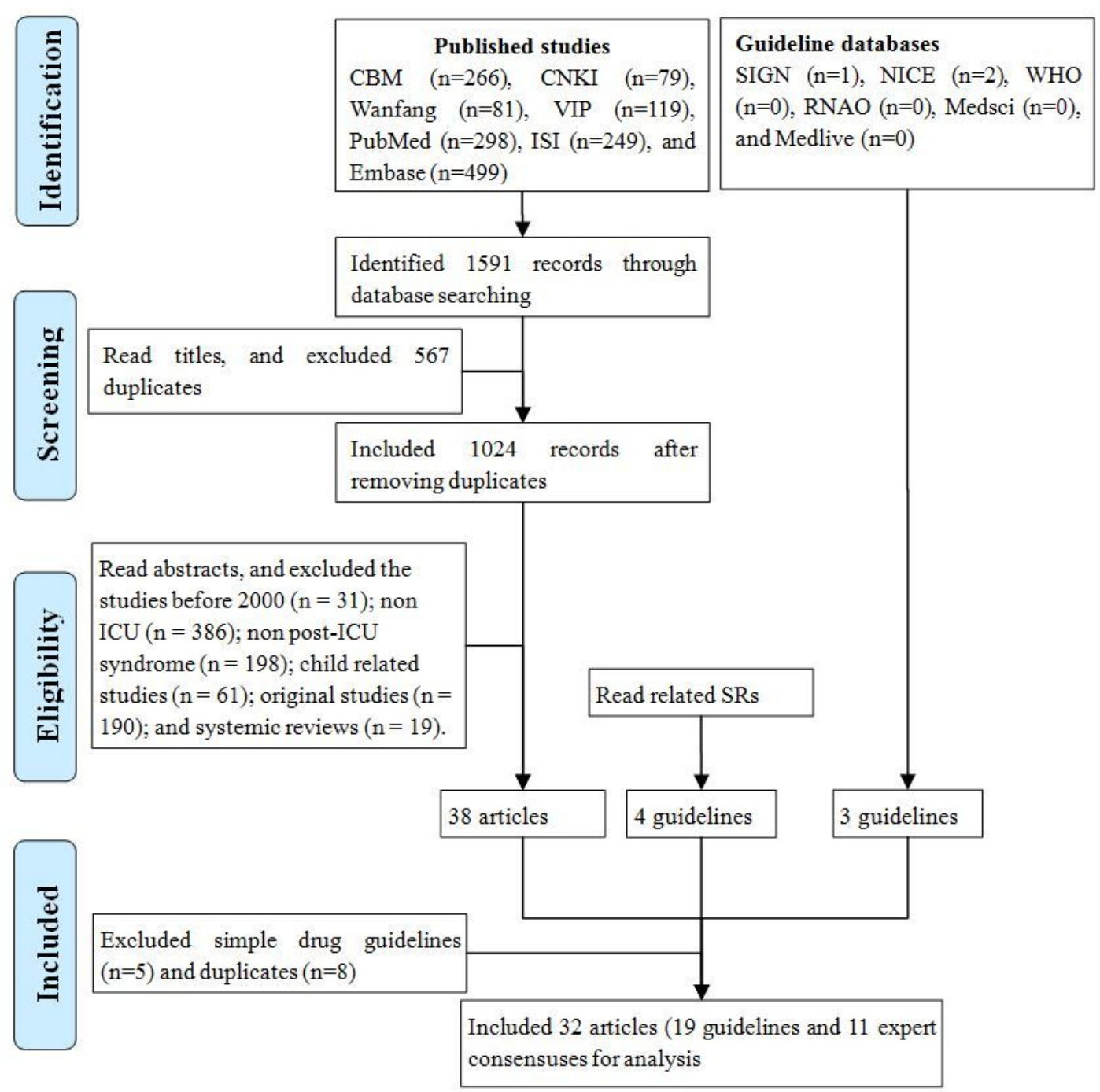

Figure 1

Articles retrieved and assessed for eligibility After excluding records that focused explicitly on medication, as well as all duplicates, 32 research papers were retained for analysis, including 19 guidelines and 11 expert consensus statements. 


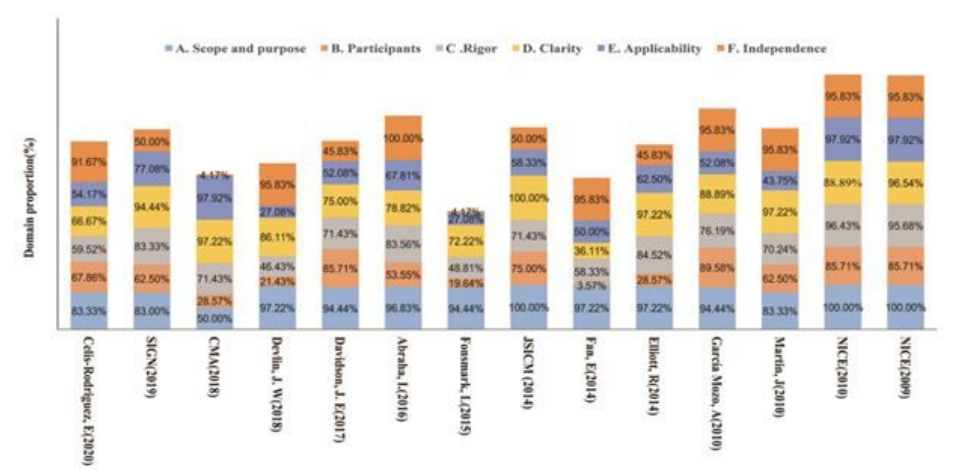

Methodological characteristics for each guideline
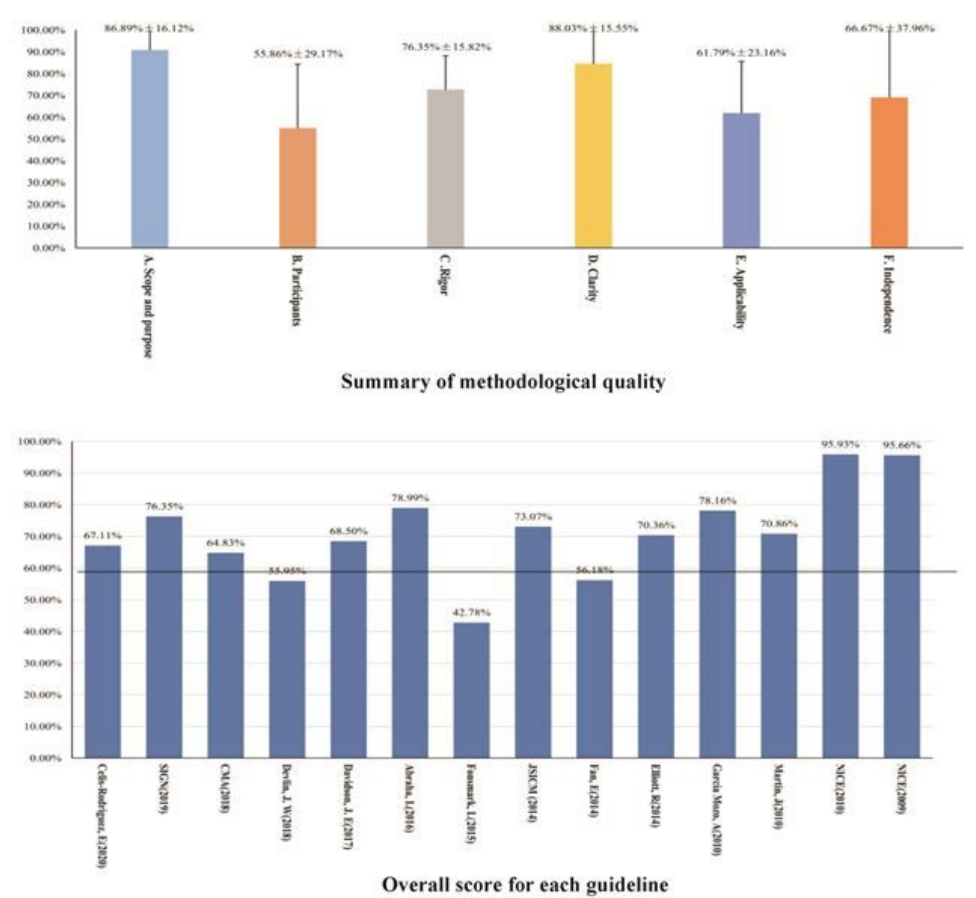

\section{Figure 2}

Methodological characteristics for guidelines The scope and purpose, rigor of development, and clarity of presentation of the investigated guidelines were of high quality. However, stakeholder involvement (participially the involvement of patients/caregivers), applicability, and editorial independence required further improvement in quality. 


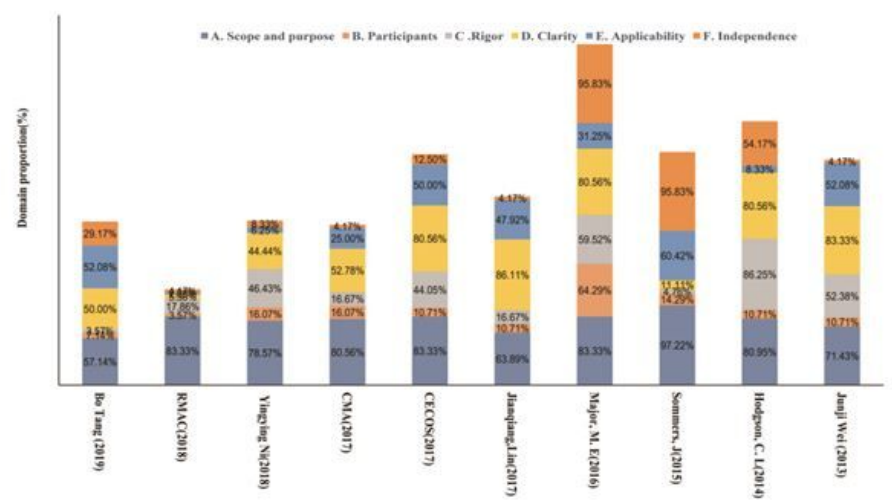

Methodological characteristics for each consensus
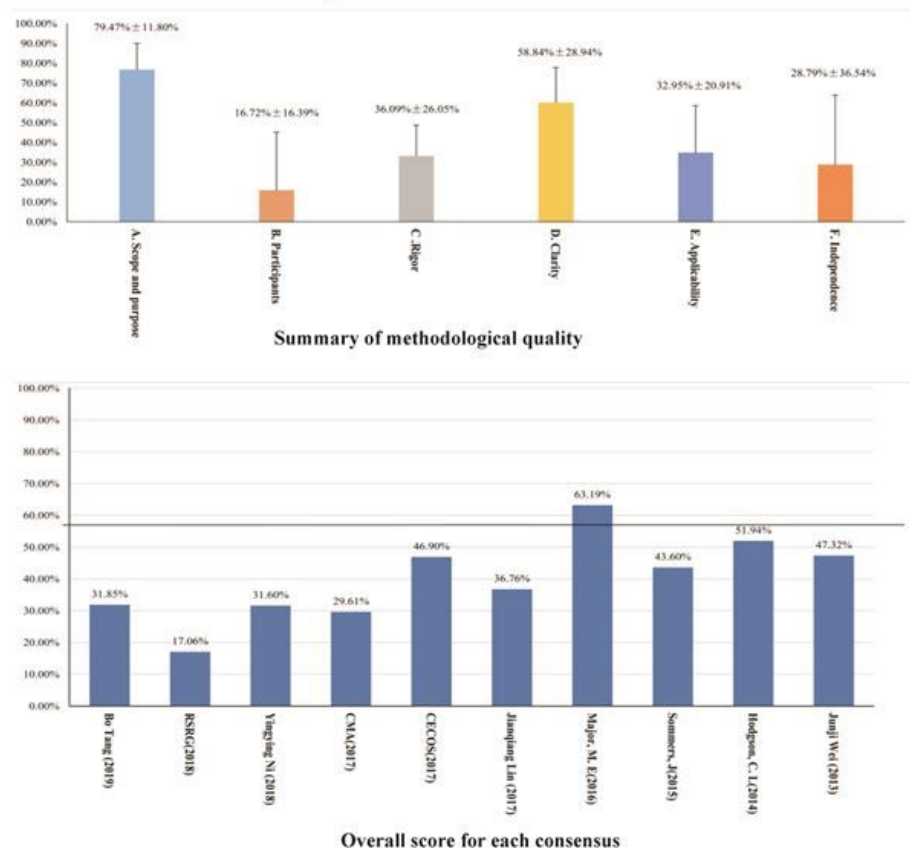

\section{Figure 3}

Methodological characteristics for expert consensuses The quality in terms of scope and purpose of the investigated consensus statements was high. However, the quality of the remaining domains, such as rigor of development, clarity of presentation, editorial independence, and applicability, was low. 


\begin{tabular}{|c|c|c|}
\hline $\begin{array}{l}\text { Hospital phase } \\
\text { (ICU) }\end{array}$ & $\begin{array}{l}\text { Hospital phase } \\
\text { (General ward) }\end{array}$ & $\begin{array}{l}\text { Hospital discharge (Primary } \\
\text { health care: community/family) }\end{array}$ \\
\hline
\end{tabular}

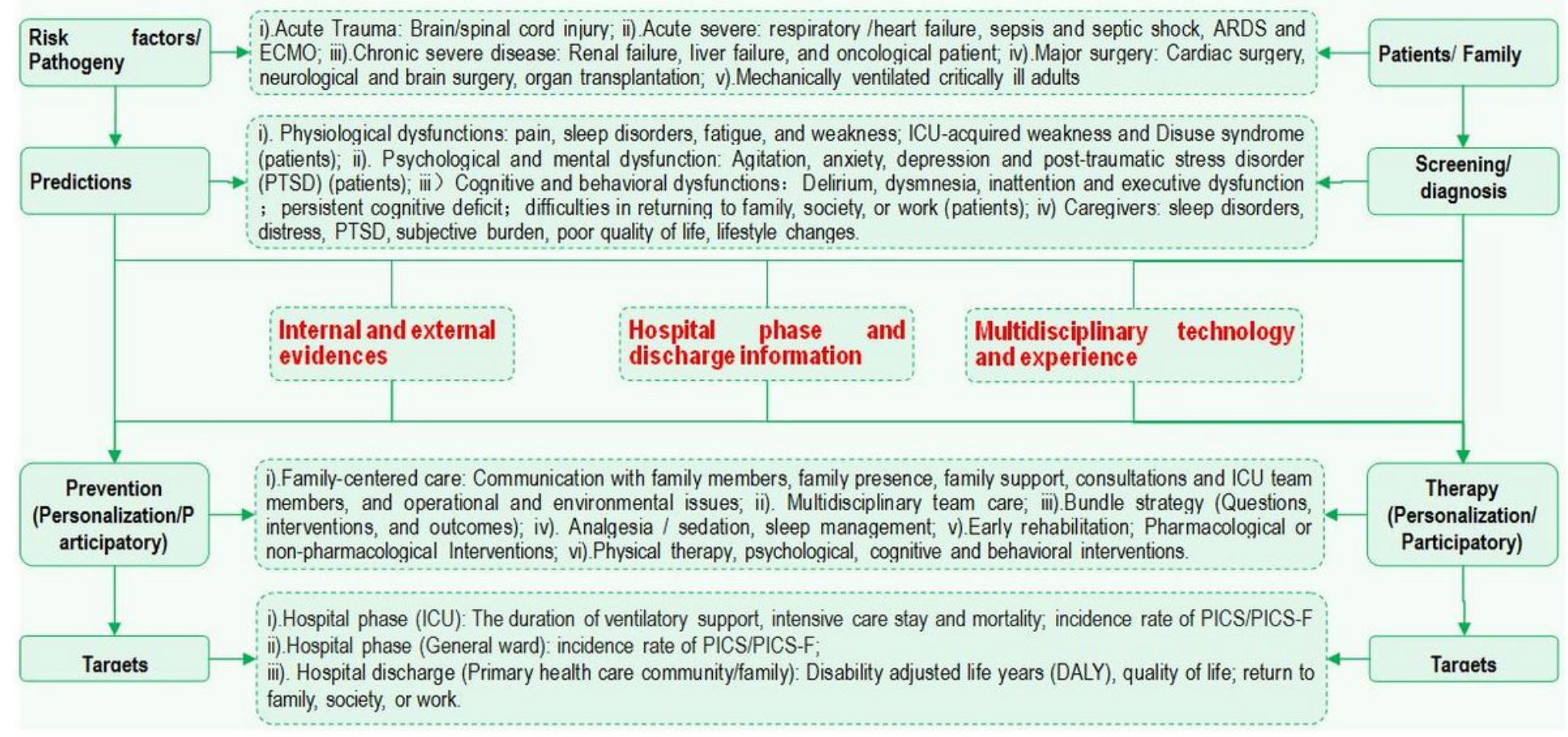

Figure 4

Evidence based prevention and management model for PICS/PICS-F Future development of guidelines and consensus statements should focus on refining the methodology, strengthening quality control, and improving presentation clarity, editorial independence, and applicability. Multidisciplinary cooperation, bundling, and evidence-based decision-making techniques should form the basis of managing guidelines/consensus statements.

\section{Supplementary Files}

This is a list of supplementary files associated with this preprint. Click to download.

- Supplementarymaterials.Retrievalresults.docx 